\title{
Fe-S Proteins Acting as Redox Switch: New Key Actors of Cellular Adaptive Responses
}

\author{
Marie-Pierre Golinelli-Cohen* and Cécile Bouton* \\ Institut de Chimie des Substances Naturelles, CNRS UPR 2301, Univ Paris-Sud, Université Paris-Saclay, 91198 Gif-sur-Yvette \\ cedex, France.
}

* To whom correspondence should be addressed: Institut de Chimie des Substances Naturelles, UPR 2301-CNRS, 1 avenue de la Terrasse 91190 Gif-sur-Yvette, France. Tel.: 33-1-69-82-30-10; Fax: 33-1-69-07-72-47; E-mail: marie-pierre.golinelli@cnrs.fr; cecile.bouton@cnrs.fr.

Running title: Fe-S proteins acting as redox switch

\begin{abstract}
Iron-sulfur (Fe-S) clusters are inorganic prosthetic groups composed of only iron and inorganic sulfur atoms with variable nuclearities. Found in all kingdoms of life, they perform numerous critical functions in fundamental processes (e.g. respiration, photosynthesis, nitrogen fixation). Organisms develop different pathways to sense their local environment such as nutrient availability, level of oxidative stress or of an element such as iron, and to respond and adapt to changes. The chemistry of Fe-S clusters makes them ideal for sensing various redox environmental signals and subsequently for mediating appropriate cellular responses. Fe-S cluster-containing sensors can lose their cluster, accommodate another type of cluster (e.g. interconversion between [4Fe-4S] and [2Fe-2S] clusters) or receive/give electrons (change in the redox state of the cluster). The present review focuses on the latter sensing mechanism, which controls the activity of Fe-S proteins in response to redox signals by change in the redox state of its cluster. Proteins using this mechanism can be found in bacteria, yeasts as well as mammals and are involved in enzyme protection (FeSII), Fe-S cluster transfer/repair (mitoNEET), DNA repair (Base Excision Repair (BER) glycosylases and helicases), and regulation of gene expression (ThnY, AirS, SoxR). In all these proteins, when the Fe$\mathrm{S}$ cluster is reduced, proteins are in a "dormant state". When their cluster perceives a signal that induces its oxidation, they switch to an "active state". This sensing mechanism efficiently helps cells to turn on survival pathways quickly and recover from stressful conditions.
\end{abstract}

Keywords: Fe-S cluster, sensor, redox state, cellular adaptive response

\section{INTRODUCTION}

Iron-sulfur (Fe-S) cluster-containing proteins are thought to have been present in the very early forms of anaerobic life. This inorganic prosthetic group is composed of iron and inorganic sulfur atoms with variable nuclearities and geometries and is extremely widespread in nature. Since their discovery in the 1960s [1], they have been found in proteins of every kingdom of life and have been shown to perform numerous critical functions in cellular processes as fundamental for life as respiration and photosynthesis [2]. Organisms often use iron-containing proteins as sensors of the environment. The iron can be directly bound to the protein (Ferric uptake regulator (Fur), PerR...), involved in heme (Dissimilative Nitrate respiration Regulator (DNR), Dos...) but also in an Fe-S cluster [3]. Indeed, the chemistry of Fe-S clusters confers on these cofactors a remarkable plasticity and makes them ideal for sensing redox environmental signals such as gases, e.g. $\mathrm{O}_{2}$ and $\mathrm{NO}$, the level of $\mathrm{Fe}$ and $\mathrm{Fe}-\mathrm{S}$ clusters, reactive oxygen species (ROS), and redox cycling compounds, and subsequently for mediating adaptive cellular responses. In response to a signal, Fe-S cluster-containing sensors can lose their cluster (e.g. cytosolic aconitase, IscR, NreB...), interconvert between Fe-S cluster types (e.g. [4Fe-4S] cluster converted into [2Fe-2S] cluster, Fumarate and Nitrate reduction Regulator (FNR), WhiB3, RirA...) or be chemically modified (Nitric oxide Sensing Rrf2-type regulator Repressor NsrR...) [4-6]. Finally, Fe-S clusters can also receive and give electrons (modulation of the iron oxidation state). Such a cluster redox modulation also stands for a potential sensing mechanism, controlling $\mathrm{Fe}-\mathrm{S}$-associated protein activity in response to redox signals. Several examples will be examined in this review, which focuses on how Fe-S cluster-containing sensor proteins act as redox switches and control a cell's rapid and efficient response to a change in its environment.

\section{Fe-S proteins}

Fe-S proteins were first detected as electron paramagnetic resonance signatures in mitochondrial membranes [1]. In 1962, the first Fe-S protein, named ferredoxin, was isolated from Clostridium pasteurianum and found to contain nonheme iron and to be involved in electron transport in different low-potential reactions [7]. Since this first discovery, it has been demonstrated that $\mathrm{Fe}-\mathrm{S}$ proteins assuming a large range of functions are present in all the kingdoms of life -in the prokaryotic archaea and bacteria as well as in the eukaryotic fungi, plants and animals- and in all cellular compartments. They are among the most ubiquitous and versatile metal-containing prosthetic centers in nature and are essential for life by sustaining fundamental processes such as photosynthesis, nitrogen fixation, respiration, DNA synthesis and repair, ribosome biogenesis, and cellular iron homeostasis $[8,9]$.

\subsection{Properties of Fe-S clusters}

Fe-S clusters are composed of one or more iron ions partially or completely coordinated by sulfur atoms. In many cases, they are associated with other types of 
cofactors such as organic groups (e.g. flavin) or other metal atoms including nickel, molybdenum, vanadium, and selenium. Fe-S clusters incorporated into proteins have different atom compositions, cluster structures and core oxidation states. The most common configurations are the [2Fe-2S], [3Fe-4S] and [4Fe-4S] core units. Interestingly, the $[2 \mathrm{Fe}-2 \mathrm{~S}]$ unit can be considered as the basic building block for the two other types of clusters; the [4Fe-4S] cluster being assembled from two $[2 \mathrm{Fe}-2 \mathrm{~S}]$ units and the $[3 \mathrm{Fe}-4 \mathrm{~S}]$ cluster from the loss of one iron of the $[4 \mathrm{Fe}-4 \mathrm{~S}]$ cluster. The tetrahedral coordination of each iron site is performed by cluster inorganic sulfides $\left(\mathrm{S}^{2-}\right)$ and proteinbased ligands, generally, thiolate groups provided by cysteine residues. However, aspartate, histidine, serine, glutamine, arginine, or small molecules (i.e. glutathione, substrate molecule, water ...) are occasionally ligand at one unique iron site [8-10].

Fe-S clusters are typically redox active, in other words they can be found in different oxidation states. Thus, each iron ion of the cluster can be either in the oxidized state, $\mathrm{Fe}(\mathrm{III})$ (ferric ion), or in the reduced state, $\mathrm{Fe}(\mathrm{II})$ (ferrous ion). [2Fe-2S] clusters are generally found only in two redox states: the oxidized form, $[2 \mathrm{Fe}-2 \mathrm{~S}]^{2+}$, with two ferric ions and the reduced form, $[2 \mathrm{Fe}-2 \mathrm{~S}]^{+}$, with one ferric ion and one ferrous ion. The all-ferrous form, $[2 \mathrm{Fe}-2 \mathrm{~S}]^{0}$, has been observed only in the case of the Rieske center [11]. The $[4 \mathrm{Fe}-4 \mathrm{~S}]$ cluster can be typically found in three redox states: $3+$ with three ferric ions and one ferrous ion, $2+$ with two ferric ions and two ferrous ions and $1+$ with one ferric ion and three ferrous ions. The all-ferrous $[4 \mathrm{Fe}-4 \mathrm{~S}]^{0}$ state was obtained in vitro using strong reducing reagents with very few proteins including nitrogenase [12]. Typically, each $[4 \mathrm{Fe}-4 \mathrm{~S}]$ protein can be found only in two redox states. The +1 and +2 levels are found in the low potential [4Fe-4S] proteins whereas the +2 and +3 levels are found in the high potential [4Fe-4S] proteins HiPIP. Finally, the [3Fe-4S] cluster can be found in the oxidized form with a global +1 charge (three ferric ions) and in the reduced form with a global charge of 0 (two ferric ions and one ferrous ion) [13].

\subsection{Functions of Fe-S proteins}

Fe-S proteins are capable of mediating biological electron transport (coupled or not to proton transfer), either through small soluble electron carriers such as ferredoxins or in membrane-bound redox enzymatic systems such as photosynthetic and respiratory electron transport chains. However, it was soon demonstrated that Fe-S clusters could also constitute the site for substrate binding and activation in a wide range of enzymes. Among these, the most characterized example is [4Fe-4S]-containing aconitase [14]. Three of the four iron atoms of the cluster are coordinated by three cysteines of the polypeptide chain and the fourth iron binds one molecule of substrate (citrate) and acts as a Lewis acid for the activation of the substrate. A similar approach is used by the members of the fast-growing and diverse radical-SAM superfamily including the biotin synthase BioB, the hydrogenase biosynthetic enzyme HydE, and the thiamine pyrimidine biosynthetic enzyme ThiC [15].
$\mathrm{Fe}-\mathrm{S}$ proteins are also involved in iron or $\mathrm{Fe}-\mathrm{S}$ cluster storage as in polyferredoxins from anaerobic bacteria and archaea [16], in disulfide reduction as in thioredoxin reductase in chloroplasts for example [17], in sulfur donation as in biotin synthase [18], in ribosome synthesis (ABCE1) and in Fe-S cluster biogenesis (IscU, IscA...) or repair (mitoNEET) [19, 20].

Until recently, zinc, a redox inactive metal, was considered as the metal of choice for nucleic acid-binding proteins ( $\mathrm{Zn}$ finger proteins). Actually, few DNA-binding proteins (the glycosylases MutY and endonuclease III) were known to contain an Fe-S cluster and it was considered that, in these proteins, the $\mathrm{Fe}-\mathrm{S}$ cluster played only a structural role similar to that of $\mathrm{Zn}$ in $\mathrm{Zn}$-finger proteins. Moreover, strong in vitro evidence suggested that they may also use their clusters to search cooperatively for damaged DNA bases within the genome [21, 22](this review). Nevertheless, during the last decade, a growing number of DNA-binding proteins including DNA helicase XPD family members, replicative DNA polymerases, the helicase-nuclease Dna2 and RNA-binding proteins including some tRNA modifying enzymes were characterized as Fe-S proteins [23, 24]. Thus, $\mathrm{Fe}-\mathrm{S}$ proteins play a major role in copying the genome and maintaining its integrity. The exact function of Fe-S clusters in the majority of these proteins has yet to be uncovered, which will be a major issue in the coming years.

Finally, Fe-S proteins are also involved in transcriptional or translational regulation of gene expression [5]. To sense different types of environmental stimuli, distinct sensing mechanisms are used, involving cluster assembly, conversion, or redox chemistry (redox switch, this review). This activity was first described in the case of the mammalian cytosolic aconitase (holoform of the protein), the apo-protein of which, iron-regulatory protein 1 (IRP-1), binds to mRNA iron-responsive elements and regulates the expression of several proteins involved in cellular iron metabolism [25]. In the case of the bacterial FNR, an oxygen-sensing transcriptional regulator, the conversion of the DNA-binding dimeric $\left[4 \mathrm{Fe}-4 \mathrm{~S}^{2+}\right.$ form to a monomeric $[2 \mathrm{Fe}-2 \mathrm{~S}]^{2+}$ form is used to control the expression of genes involved in the respiratory pathways [26]. Finally, as discussed below, intracellular oxidative stress converts the reduced inactive SoxR into a transcriptional activator of soxS gene, which is responsible for activating the transcription of numerous enzymes in the oxidative stress response [27].

\section{Fe-S cluster proteins acting as redox switches}

2.1. Enzyme protection: case of the FeSII protein (Shethna protein II)

Nitrogen is an essential component of all living organisms because it is present in nucleic acids, proteins and many other biological molecules. Although molecular nitrogen $\left(\mathrm{N}_{2}\right)$ gas is abundant in air, it cannot be readily used by most organisms. Typically, they use ammonia as substrate for insertion of nitrogen in molecules. Thus, the reduction of $\mathrm{N}_{2}$ to ammonia (nitrogen fixation) is a key process for the synthesis of many organic compounds and is one of the most common ways to make nitrogen available for plants. 
Biological nitrogen fixation is catalyzed by the nitrogenase present in some microorganisms known as diazotrophs, mainly bacteria such as Azotobacter species [28]. Nitrogenase is composed of two proteins, the Fe protein and the $\mathrm{MoFe}$ protein. Both proteins contain complex $\mathrm{Fe}-\mathrm{S}$ clusters and are irreversibly inactivated by oxygen within minutes by irreversible oxidation of their clusters [29].

Azotobacter species are obligatory aerobic nitrogen-fixing organisms and they develop two main mechanisms to protect nitrogenase from in vivo inactivation by oxygen. When this organism fixes $\mathrm{N}_{2}$ during energy-supplemented growth, its respiratory system increases to reduce the concentration of intracellular dioxygen (respiratory protection). But, in the case of oxygen stress or under substrate-limiting conditions, this protection ceases to be effective, and nitrogenase is rapidly and reversibly inhibited (temporary conformational protection) [30]. Thus, in crude A. vinelandii extracts, nitrogenase is more resistant to $\mathrm{O}_{2}$ than the purified enzyme. Analysis of this $\mathrm{O}_{2}$-insensitive inactive nitrogenase form shows that the two components of nitrogenase are complexed to a small [2Fe-2S] protein known as FeSII or Shethna protein II [30-32]. FeSII protein is not essential for anaerobic nitrogen fixation of $A$. vinelandii [33] but strains lacking FeSII lose viability upon carbon substrate deprivation in the presence of oxygen [34]. In vitro studies show that only the oxidized holo-FeSII can form a complex with the two components of nitrogenase (oxidation state-dependent interaction) [35]. This complex is more resistant to oxygen than nitrogenase alone, but is inactive ("switch off state")[36, 37]. In favorable redox conditions, the cluster of FeSII is reduced and the protein dissociates from nitrogenase and its activity recovers [35]. A similar protective mechanism was described in a few other diazotrophs such as Gluconacetobacter diazotrophicus, which plays a major role in the supply of nitrogen to sugar cane [38].

The crystallographic structure of $A$. vinelandii FeSII [37] shows that this small dimeric protein is present in the crystal in two distinct states that differ only in the conformation of an extended loop in close proximity to the Fe-S cluster ("Nloop" from Gly59 to Pro96) whereas, in the "closed state", the cluster is shielded by a helix of the N-loop. When in the "open state", the helix moves away from the cluster, revealing a new protein surface and increasing the solvent accessibility of the cluster. Gel filtration analysis demonstrates that the oxidized form has a larger hydrodynamic radius than the reduced form. Thus, the "open form" was attributed to the oxidized form and the "closed form" to the reduced one. A model of the complex between FeSII and nitrogenase was built from each crystal structure and clearly, only the "open state" (oxidized) FeSII was able to insert into the cleft between the two components of nitrogenase, leaving the $\mathrm{Fe}-\mathrm{S}$ cluster accessible to the solvent and to reduction. Thus, the oxidation of the cluster of FeSII protein induces a conformational change that allows the FeSII protein to bind reversibly to nitrogenase and to protect it from oxygen with a still ill-defined mechanism (simple induction of conformational switch of the complex or a more active role in the protection of nitrogenase) (Fig. 1). After stress relief, reduced FeSII dissociates from nitrogenase, the activity of which is restored.

\subsection{Fe-S repair proteins: case of the NEET proteins}

NEET proteins are present in all the kingdoms of life. They are characterized by the presence of at least one highly conserved 39-amino-acid motif called CDGSH Iron-Sulfur Domain (CISD) and involved in the coordination of a [2Fe$2 \mathrm{~S}$ ] cluster coordinated by 3 cysteines and one histidine. In mammals, this family is composed of three members: mitoNEET (CISD1), Miner1 (CISD2, ERIS, Noxp70 or NAF-1), and Miner2 (CISD3). MitoNEET and Miner1 are dimers that assemble one cluster per monomer whereas Miner2 is monomeric and assembles two clusters. In plants and bacteria, NEET orthologs are similar to mitoNEET/Miner1 and Miner2, respectively [39, 40].

MitoNEET is anchored to the mammalian outer mitochondrial membrane (OMM) by its $\mathrm{N}$-terminus with the major part of the protein, including the C-terminal [2Fe-2S]binding domain, located in the cytosol [41]. This is the first identified Fe-S protein of the OMM. Its biological activity is still debated [42], but several studies have shown that this protein is involved in the regulation of iron and ROS homeostasis [20, 41, 43, 44], in cell proliferation in human breast cancer [45], and in lipid accumulation in adipocytes without insulin resistance [43]. Miner1 is anchored by its Nterminus at the endoplasmic reticulum (ER) membranes and at contact sites between mitochondria and ER (MAM)[46]. Miner1 could be involved in neuronal development [47], in the regulation of autophagy through its interaction with $\mathrm{Bcl} 2$ [48] and of apoptosis [49], in the homeostasis of intracellular calcium [50], in the maintenance of the integrity of mitochondria and lifespan [51] and in the inflammatory response [52]. Recessive mutations in CISD2 gene coding for Minerl are the cause of Wolfram syndrome 2 (or WFS-2), a neurological disease characterized by at least optical atrophy and diabetes [53-55]. Finally, like mitoNEET, a strong link was noted between a high level of expression of Miner1 and fast proliferation of various cancer cells [56], which makes Miner1 a new marker of negative prognosis for various cancers [57]. Miner2 is less characterized than the two other NEET proteins. It seems to be mostly localized to the mitochondria, and it might also be involved in cellular proliferation $[41,58]$.

Crystallographic studies of the overexpressed soluble Cterminal domains of mitoNEET and Miner1 revealed a similar unique folding for both proteins. Both form dimers with two distinct domains, a $\beta$-cap and an Fe-S cluster binding domain. Both structures slightly differ in the $\beta$-cap domain. Each monomer accommodates one [2Fe-2S] cluster coordinated by three cysteines and one histidine [59-63] and they have very similar UV-visible absorption spectra. The cluster of mitoNEET is $\mathrm{pH}$ labile and redox-active with a midpoint redox potential of roughly $0 \mathrm{mV}$ at $\mathrm{pH} 7$ [62-65]. The reduced form, which is very likely present in quiescent mammalian cells holds a $[2 \mathrm{Fe}-2 \mathrm{~S}]^{+}[44,62,66]$ and is 
extremely stable and cannot lose its cluster. The latter can be reversibly oxidized by hydrogen peroxide and reduced by biological thiols implying a redox sensory function of mitoNEET [44, 67]. Recently, we have shown that the cluster of the oxidized mitoNEET is relatively stable and that oxygen strongly increases its lability [66].

In vitro, mitoNEET and Miner1 are both able to transfer their $\mathrm{Fe}-\mathrm{S}$ cluster to an apo-protein receptor (an $\mathrm{Fe}-\mathrm{S}$ protein that has lost its Fe-S cluster) of various origins [20, 42, 66, 68]. The His ligand is critical for cluster release and transfer [69-71]. In cellulo, mitoNEET can transfer its cluster to the human IRP-1/cytosolic Fe-S aconitase, a key regulator of cellular iron homeostasis after oxidative damage of its cluster. We proposed that mitoNEET is involved in the repair of oxidatively damaged IRP-1/aconitase and possibly in a more general repair pathway of damaged cytosolic Fe-S protein [20]. Initial studies on mitoNEET/Miner1 suggested that the transfer can occur only if the cluster is oxidized [69]. Recently, by decoupling the oxygen effect from the cluster redox effect, we have proven that only oxidized mitoNEET cluster triggers its transfer to a model receptor protein, independently of the presence or absence of oxygen and without major protein rearrangement between the two redox state of the protein [66].

Then, we proposed a model (Fig. 2) for a new Fe-S cluster repair pathway involving mitoNEET. In the absence of stress, mitoNEET would be reduced. Oxidative stress damages $\mathrm{Fe}-\mathrm{S}$ clusters of proteins and oxidizes the mitoNEET Fe-S cluster. If the damaged $\mathrm{Fe}-\mathrm{S}$ cluster protein is not degraded after loss of its cluster (i.e. IRP-1/caconitase), oxidized mitoNEET can then transfer its cluster to the damaged protein. This newly discovered repair pathway might allow very fast recovery of key Fe-S protein activity after stress.

\subsection{DNA repair enzymes}

\subsubsection{BER glycosylases}

Cellular DNA is constantly attacked by damaging agents including ROS. Cells have developed efficient DNA repair pathways in order to maintain genome integrity. BER is a highly conserved pathway from prokaryotes to eukaryotes involved in removing a large variety of DNA lesions including oxidation, deamination, depurination, alkylation and single-strand break. DNA glycosylases are key components of this repair pathway. They first search for and detect DNA damage among the vast excess of undamaged bases and then cleave the glycosidic bond between damaged base and sugar, leaving an abasic site that is further processed by downstream enzymes to restore the undamaged DNA [72]. Several BER glycosylases assemble a [4Fe-4S] cluster including the $E$. coli endonuclease III (Endo III) [73, 74] and MutY [75, 76], Microccus luteus UV endonuclease [77], Methanobacterium thermoautotrophicum G:T-specific thymine glycosylase [78], Thermotoga maritima methylpurine glycosylase [79], and uracil DNA glycosylases (UDG) from thermophile and hyperthermophilic organisms $[21,23,80]$. Until now, their human homologs have not been studied extensively but, clearly, mammalian hNTH1 and MUTYH, homologs of Endo III and MutY respectively, assemble a [4Fe-4S] cluster [81-84].

The first BER glycosylase reported as an Fe-S-containing protein is Endo III from E. coli. The purified enzyme contains a single $[4 \mathrm{Fe}-4 \mathrm{~S}]^{2+}$ that cannot be reduced under physiological conditions or oxidized without cluster degradation. Thus, the Fe-S cluster was thought to be redoxinactive [73]. The apo-form of MutY is globally folded but is completely inactive and its activity can be restored by chemical cluster reconstitution [85]. Moreover, mutagenesis of the cluster ligands decreases their DNA-binding affinity [86]. The crystal structures of E. coli Endo III [87], E. coli MutY [75] and Thermus thermophilus UDG [88] show that the polypeptide forms a solvent exposed loop (iron-sulfur cluster loop, FCL) between two cysteines involved in the coordination of the cluster. This loop contains numerous positively charged residues. The crystal structures of these enzymes bound to DNA substrate reveal that the cluster is necessary to properly position conserved basic residues from the FCL to interact with the DNA phosphate backbone [89-91]. The importance of these residues of FCL in enzyme binding to substrate and activity was confirmed by sitedirected mutagenesis [74, 92, 93]. Thus, the Fe-S cluster clearly plays, at least, a structural role in these $\mathrm{Fe}-\mathrm{S}$ clustercontaining glycosylases. Interestingly, MutY lacks the [4Fe4S] cluster in bacteria such as Lactobacillaes as well as in the protozoan genus Entamoeba. In these organisms, loss of the cluster is compensated for by bulky amino acids that stabilize the structure in a similar manner [94].

The pioneering work of Barton and David's laboratories has led to a reexamination of the role of the Fe-S cluster in these glycosylases [21, 22]. Using DNA-modified gold electrodes, they first showed that the binding of $[4 \mathrm{Fe}-4 \mathrm{~S}]^{2+}$-MutY to DNA shifts the redox potential of the $+3 /+2$ couple into the physiological range (roughly $80 \mathrm{mV}$ vs. Normal Hydrogen Electrode, NHE) and makes the cluster more easily oxidized (redox active cluster) [95]. Thus, the binding of the protein to DNA allows the oxidation of its cluster and the release of an electron. Similar observations were made with Endo III and UDG [96]. Moreover, they observed that the DNAbinding affinity of the $[4 \mathrm{Fe}-4 \mathrm{~S}]^{2+}$-MutY is much lower than that of the oxidized form (DNA-binding affinity controlled by the redox state of the cluster) [96].

Guanine radicals are frequent oxidative DNA lesions generated by ROS. Interestingly, by their very high redox potential, they facilitate the oxidation of DNA-bound MutY and initiate the binding of MutY in the vicinity of oxidized DNA [97]. The intact double helix structure of DNA, with $\pi$-stacked base pairs, allows charge transfer $(\mathrm{CT})$ along DNA between two redox partners over at least $200 \AA$ and displays sensitivity to mismatched or damaged base pairs such as abasic sites that disturb the $\pi$-staked array. Interestingly, MutY and EndoIII exhibit a diminished electrochemical signal with an electrode modified with DNA containing an abasic site $[95,96]$, suggesting that DNA-mediated CT is necessary for the redox-controlled activity of MutY and EndoIII through Fe-S clusters [95, 96, 
98].

Taken together, a model for BER enzymes scanning DNA for damaged bases using DNA-mediated CT has been proposed (Fig. 3). A highly oxidizing guanine radical in DNA oxidizes a cluster of MutY and initiates binding of the enzyme to the DNA. The electron released during this oxidation process can reduce a distally bound protein using DNA-mediated CT by intact DNA between the two proteins. The newly reduced protein then dissociates from the DNA. As a consequence, local concentrations of MutY/EndoIII remain low where DNA is not damaged. If DNA is damaged, the CT cannot occur and both proteins remain bound to DNA on both sides of the lesion (higher local concentration of glycosylases around the DNA damage) and can slide along DNA using a processive mechanism without dissociation of the enzyme and, subsequently, repair the damage [99]. This mechanism allows glycosylases, only 30-500 copies of which are found per bacterial cell, to localize DNA damage rapidly and relocate in the surrounding vicinity $[22,100,101]$.

\subsubsection{XPD/XPD-like helicases and AddB-type} nucleases

XPD is an ATP-dependent super-family 2 DNA helicase with 5'-3' polarity. In eukaryotes, it is a component of the transcription factor TFIIH complex and is involved in DNA repair by the Nucleotide Excision Repair (NER) pathway. XPD opens the DNA around the lesion in an ATPdependent fashion and then additional NER factors are recruited. The presence of a $[4 \mathrm{Fe}-4 \mathrm{~S}]$ cluster was first shown in XPD from the archaea Sulfolobus acidocaldarius [102] then XPD-like helicases were further found in all kingdoms of life including Rad3 in yeast [103], E. coli DinG [104] and human Rtel1 [105]. Typically, the cluster is essential for the helicase activity and to couple ATP hydrolysis to DNA translocation [102-104, 106, 107]. Moreover, an Fe-S cluster was also found in AddB-type nuclease of the AddAB helicase-nuclease complex from Bacillus subtilis [106], as well as in the yeast bifunctional helicase-nuclease protein Dna2 involved in Okazaki fragment processing during DNA replication [107]. Crystal structures of archaeal XPD [108-111] and of bacterial AddAB bound to DNA [112] show that the cluster is involved in the formation of a FCL-type domain between two ligands of the Fe-S cluster similar to the one found in $\mathrm{Fe}-\mathrm{S}$ cluster-containing glycosylases. Moreover, crystal structures revealed a four-domain organization of the helicases with the two motor domains (HD1 and HD2), $\mathrm{ARCH}$ and Fe-S domains with the HD1, ARCH and Fe-S domains forming a channel critical for ssDNA translocation during XPD helicase unwinding [113].

Thus, the cluster plays a structural role in maintaining local conformations that are critical for enzyme activity, but is also redox active (redox potential of the $+2 /+1$ couple around $400 \mathrm{mV}$ vs. NHE) [104, 105, 110]. Actually, in vitro reduction of the $[4 \mathrm{Fe}-4 \mathrm{~S}]^{2+}$ cluster of $E$. coli DinG reversibly switches off its helicase activity [104]. Moreover, both the cluster and the helicase activity are resistant to high concentrations of hydrogen peroxide, whereas exposure to NO reversibly inactivates the enzyme in vitro by formation of a DinG-bound dinitrosyl iron complex (DNIC). Thus, these results suggest that the cluster might also act as a sensor of intracellular redox potential to modulate its helicase activity [104].

Finally, experiments using DNA-modified electrodes showed that DNA binding shifts the $3+/ 2+$ redox potential of the helicase to roughly $80 \mathrm{mV}$, a redox potential similar to the one previously measured for the $\mathrm{Fe}-\mathrm{S}$ clustercontaining glycosylases [114]. Moreover, redistribution of XPD around DNA damage, which inhibits $\mathrm{CT}$, was observed [115]. Then, the model of DNA scanning and repair by $\mathrm{Fe}-\mathrm{S}$ cluster-containing glycosylases using DNAmediated $\mathrm{CT}$ was extended to XPD-type helicases and even to UvrC, a NER endonuclease containing an Fe-S cluster [116]. In this extended model, XPD-type helicase, EndoIII/MutY glycosylase and UvrC have similar redox potentials and cooperate at long range using DNA-mediated CT for repair protein redistribution around DNA damage $[115,117,118]$. This DNA-mediated signaling among different DNA repair pathway enzymes was also demonstrated to be critical to maintenance of the integrity of the bacterial genome under stress conditions [117].

Finally, it was shown that all replicative DNA polymerases (POL $\alpha$, POL $\delta$, POL $\varepsilon$ ), but also the primase subunit PRIM2, assemble an Fe-S cluster $[119,120]$. Preliminary studies showed that PRIM2 is able to also mediate DNA CT [121]. Thus, it was proposed that DNA-mediated CT might be a mechanism largely used by all these Fe-S cluster-containing DNA synthesis and repair enzymes to interrogate DNA integrity, to communicate rapidly and to coordinate their activities efficiently by modulating the redox state of their cluster [23].

\subsection{Regulators of gene expression}

2.4.1.ThnY/ThnR, regulators of the tetralin degradation pathway

In response to the presence of the organic solvent tetralin (1,2,3,4-tetrahydronaphthalene), the expression of the thn $\mathrm{A}$ genes of the Gram-negative Sphingomonas macrogolitabida strain TFA allows the utilization of this compound as a carbon and energy source (tetralin biodegradation) [122, 123]. The catabolism pathway involves the ferredoxin reductase ThnA4, the Rieske-type ferredoxin ThnA3, and the dioxygenase ThnA1/ThnA2 forming an electron transfer chain from the NAD $(\mathrm{P}) \mathrm{H}$ to the tetralin substrate [123].

The regulation of the expression of the four thnA genes is complex and involves two proteins of the catabolic pathway, ThnA4 and ThnA3, the LysR-type transcriptional activator ThnR and ThnY. ThnY is an Fe-S flavoprotein containing an FAD-binding site and a plant ferredoxin-like [2Fe-2S] cluster, sharing homology with bacterial oxygenase-coupled $\mathrm{NAD}(\mathrm{P}) \mathrm{H}-$ dependent ferredoxin reductases (enzymes that play an important role in the degradation of aromatic compounds) [124-126]. Clearly, ThnR and ThnY are both essential for tetralin biodegradation $[124,126]$. ThnR activates thnA gene transcription by binding to promoter 
regions [126]. In vitro, oxidized ThnY binds to ThnR and enhances the DNA-binding affinity of ThnR by modifying the structure of the ThnR-DNA complex, most likely through direct interaction with ThnR [125]. Mutations of residues involved in the coordination of the Fe-S cluster or in the FAD-binding region of ThnY allow the transcription of the thnA genes in response to compounds other than tetralin (loss of the specificity of the pathway), suggesting that ThnY cofactors are important for tetralin response specificity [127]. Finally, it has been proposed that the redox state of the ThnY cluster might modulate the protein activity under the regulation of the ferredoxin ThnA3 [125]. Interestingly, similar poor substrate specificity was observed in a strain deleted for ThnA3, a protein of the catabolic pathway [127]. Moreover, in the absence of a good substrate for the dioxygenase or in conditions when reduced ThnA3 presumably accumulates, the expression of thnA genes is blocked, indicating communication between the regulatory and catabolic pathways $[127,128]$.

The whole regulatory cascade leading to the specific expression of thnA genes only in the presence of tetralin was recently described (Fig. 4) [129]. It is proposed that in presence of tetralin, the catabolic pathway is very efficient and that electrons from $\mathrm{NAD}(\mathrm{P}) \mathrm{H}$ are transferred to ThnA4, then to ThnA3 and finally to the dioxygenase ThnA1/ThnA2, which degrades the substrate. In this case, the substrate acts as an electron sink. ThnY is mostly oxidized, binds to ThnR and stimulates its binding to DNA. Conversely, at low tetralin concentration or in the presence of a non-optimal substrate for the dioxygenase, electrons from NAD $(\mathrm{P}) \mathrm{H}$ that accumulate in ThnA3 are redirected towards ThnY (ThnY reduction) instead of the dioxygenase. The binding of reduced ThnY to ThnR is thus impaired and thnA gene expression is not induced by ThnR.

\subsubsection{The bacterial redox-sensor histidine kinase, AirS} Bacteria frequently sense numerous environmental signals and respond rapidly through sophisticated informationprocessing two-component signaling (TCS) pathways that exhibit complex dynamics on different timescales. Typically, these pathways involve a sensor histidine kinase that autophosphorylates in response to a given stimulus, and then transfers its phosphate group to a cognate response regulator that initiates appropriate cellular responses [130]. Among them, the FixL/NreB $\mathrm{O}_{2}$-sensor kinase family members are iron-containing proteins [131]. The FixL subfamily uses heme as sensor while the NreB subfamily, including $\mathrm{NreB}$ and AirS, uses an Fe-S cluster.

Staphylococcus aureus is a facultative anaerobe, which is able to invade almost every kind of tissue and to adapt to diverse hypoxic conditions, including the highly hypoxic environment at the onset of inflammation. Thus, bacteria have different sensing mechanisms, including TCS pathways, to adapt to oxygen availability and to use either nitrate respiration or carbohydrate fermentation $[132,133]$. The AirS-AirR TCS of S. aureus (AirS is the kinase; AirR is the transcriptional regulator), also known as YhcSR, is essential for growth of the bacteria in culture [134] and for its pathogenesis [135]. It is a global key regulator that controls the transcription of more than 350 genes [136], including regulation of the nitrate respiratory pathway [137], of cell wall synthesis [138], and of various virulence factors [136]. It is also involved in the resistance to ROS induced by the host immune system by upregulation of the production of the antioxidant molecule staphyloxanthin [139] and, more generally, it contributes to bacterial survival in human blood [135].

In vitro studies demonstrate that the membrane-bound histidine kinase AirS coordinates a [2Fe-2S] cluster with four cysteine ligands acting both as an oxygen- and a redoxsensor [136]. Under anaerobic conditions (Fig. 5), AirS cluster is in the reduced state $[2 \mathrm{Fe}-2 \mathrm{~S}]^{1+}$ and AirS kinase activity is low (low concentration of phosphorylated AirR). The unphosphorylated AirR represses transcription of genes involved in bacterial virulence, including the quorum-sensing TCS Agr, the virulence TCS SaeRS, and some other stress-associated factors [136]. Oxidation of the cluster to the $[2 \mathrm{Fe}-2 \mathrm{~S}]^{2+}$ state leads to efficient AirS kinase activity (optimal phosphorylation of AirR). However, prolonged exposure to oxygen, intense host-generated ROS, or contact with reactive nitrogen species (RNS) leads to inactive AirS (Apo-AirS and DNIC forms for oxidative and NO stresses, respectively [136]), and accumulation of unphosphorylated AirR. Thus, AirS is capable of sensing oxygen and redox signals through its $\mathrm{Fe}-\mathrm{S}$ cluster, which is essential for its kinase activity. This redox-dependent kinase activity of AirS allows AirRS TCS to play an important role in appropriately coordinating and rapidly synchronizing virulence determinant production in response to the host environment.

\subsubsection{SoxR}

The SoxRS system found in enteric bacteria such as E. coli is another two-part regulatory system [140, 141]. It is involved in a global response to exogenous oxidative and nitrosative stresses by controlling the expression of more than 100 genes involved in redox homeostasis, damage repair, multidrug resistance, and heavy metal detoxification $[142,143]$. First, SoxR is activated in response to an oxidative stress in a superoxide-independent manner [144], and switches on the transcription of the global regulator SoxS, which activates the soxRS regulon $[145,146]$. SoxS homologs do not exist in nonenteric bacteria such as Pseudomonas aeruginosa and Streptomyces coelicolor. Thus, in these antibiotic producer bacteria, SoxR is believed to regulate directly the transcription of a small set of genes that protect the bacterium against excreted endogenous redox-active antibiotics involved in quorum-sensing, inhibition of competitor bacteria, and bacterial virulence during infection [147-151].

SoxR is a small protein of the MerR family of transcriptional sensors that forms a dimer in solution and assembles a $[2 \mathrm{Fe}-2 \mathrm{~S}]$ cluster fully coordinated by cysteine residues in the C-terminal domain of each monomer [152, 153]. The crystal structure of SoxR alone or in complex with soxS promoter DNA showed a protein folding similar that of other MerR proteins (DNA-binding domain, sensor domain, and coiled-coil dimerization domain), but with 
cluster irons exposed to the solvent with an asymmetric electrostatic environment [154]. The Fe-S cluster present in the sensor domain of SoxR can be found in the +1 and +2 oxidation states, with a midpoint potential around $-285 \mathrm{mV}$ vs. NHE $[155,156]$. SoxR can bind DNA with similar affinity independently of the absence (apo-form) or presence of the Fe-S cluster [152], and of its redox state (oxidized vs. reduced). Still, only the oxidized holo-SoxR can activate the transcription of SoxS $[155,156]$.

During normal aerobic growth, the SoxR cluster is clearly reduced in $E$. coli [157]. Using DNA-modified electrodes, it was proposed that the binding of SoxR to its cognate DNA shifts its redox potential to $+200 \mathrm{mV}$ [158]. As a consequence, only a strongly oxidizing environment would be able to oxidize the cluster quickly and to activate SoxR and the transcription of the soxS operon [144]. Interestingly, SoxR from different organisms exhibit various sensitivities to redox-cycling agents depending on the redox potential of their Fe-S cluster, which is affected by changes in a few residues around the cluster [159]. It has been also reported that SoxR can be activated by DNA-guanine radicals and DNA-mediated charge transfer [160], which can provide rational bases for rapid activation of SoxR. Finally, SoxR can be activated by exposure to macrophage-generated NO followed by nitrosylation of its $\mathrm{Fe}-\mathrm{S}$ cluster resulting in SoxR-bound DNIC [161-163].

SoxR cluster oxidation induces a protein conformational change with interdomain reorganization [164] and significant distortion and underwinding of the SoxR-bound DNA [165] that improves RNA polymerase binding and further increases transcription $[166,167]$. When the stress is over, the SoxR cluster is rapidly reduced by $\operatorname{rsx} A B C D G E$ and $r s e C$ gene products [168] and SoxS is subject to proteolytic degradation [169], ensuring that the system's response remains dependent on the signal (Fig. 6).

Recently, it was proposed that the Streptomyces venezuelae NsrR homolog RsrR for Redox sensitive response Regulator assembles a redox active [2Fe-2S]. It is believed that its cluster controls its DNA-binding ability in a similar manner to SoxR (the oxidized form binds DNA more efficiently) and regulates $\mathrm{NADH} / \mathrm{NAD}(\mathrm{P}) \mathrm{H}$ and glutamate/glutamine pathways [170].

\section{REMARKS AND CONCLUSION}

Upon hyperactivation or insult, cells classically respond by activating different pathways that promote protection such as activation of the heat shock pathway or of the unfolded protein response pathway, and eventually, cell defense, survival and recovery. However, if this typical adaptive response fails, cell death programs are activated to eliminate damaged cells.

In this review, we have examined $\mathrm{Fe}-\mathrm{S}$ proteins with different cluster nuclearity ([2Fe-2S] or [4Fe-4S]) from organisms as diverse as bacteria, yeast and mammals, with disparate cellular functions including enzyme protection (FeSII), Fe-S cluster repair (mitoNEET), DNA repair (BER glycosylases and helicases), and transcriptional regulation (ThnY, AirS and SoxR) (Fig. 7). Despite all these differences, a common point emerges: they are inactive when their Fe-S cluster is in the reduced state, which confers on the protein a state of dormancy. Upon sensing a signal (typically change of oxygen tension or oxidative stress), the cluster becomes oxidized and the protein turns to the "active state". This general mechanism appears to be a very efficient way for the cell to turn on survival pathways to recover quickly from stressful conditions. An emblematic example is given by the bacterial nitrogenase, which is irreversibly inactivated by oxygen due destruction of its Fe$\mathrm{S}$ cluster. As developed above, by forming a reversible complex with nitrogenase during oxidative stress, FeSII allows fast recovery of nitrogenase activity by simple dissociation of the complex as the stress disappears. Likewise, in mammals, the cytosolic aconitase loses its Fe-S cluster after suffering from oxidative or nitrosative stress. In the absence of mitoNEET, the Fe-S cluster biogenesis pathway would have to synthesize a new cluster before supplying it to aconitase. Instead, the reduced cluster of dormant mitoNEET can benefit from oxidative stress to become oxidized and quickly to replenish Fe-S-damaged aconitase with an intact [4Fe-4S] cluster. These last two examples are illustrative of general situations in which cells keep protective responses silent, but are ready to be activated promptly as soon as a single electron is transferred to $\mathrm{Fe}-\mathrm{S}$ cluster. Such rapid and efficient stress response systems underline once again how the exceptional electronic properties of $\mathrm{Fe}-\mathrm{S}$ clusters are being used by living organisms and permit subtle tuning of $\mathrm{Fe}-\mathrm{S}$ proteins properties. In conclusion, $\mathrm{Fe}-\mathrm{S}$ cluster proteins acting as redox switch appear as new key actors of very efficient and rapid cellular reactions that help cells to restore their activity after a change in environment.

$\begin{array}{ll}\text { LIST OF ABBREVIATIONS } \\ \text { BER } & \text { Base excision repair } \\ \text { CISD } & \text { CDGSH Iron-Sulfur Domain } \\ \text { CT } & \text { Charge transfer } \\ \text { DNIC } & \text { Dinitrosyl iron complex } \\ \text { Endo III } & \text { Endonuclease III } \\ \text { FCL } & \text { Iron-sulfur cluster loop } \\ \text { FNR } & \text { Fumarate and Nitrate reduction Regulator } \\ \text { IRP-1 } & \text { Iron-Regulatory Protein-1 } \\ \text { NER } & \text { Nucleotide Excision Repair } \\ \text { NHE } & \text { Normal Hydrogen Electrode } \\ \text { OMM } & \text { Outer mitochondrial membrane } \\ \text { RNS } & \text { Reactive nitrogen species } \\ \text { ROS } & \text { Reactive oxygen species } \\ \text { TCS } & \text { Two-component signaling } \\ \text { UDG } & \text { Uracil DNA glycosylase }\end{array}$

\section{CONFLICT OF INTEREST}

The authors declare that they have no conflicts of interest with the contents of this article.

\section{ACKNOWLEDGEMENTS}

We are grateful to Cécile Mons and Drs. Jean-Claude Drapier, Ewen Lescop (ICSN) and Laurence Vernis (Institut Curie) for many fruitful discussions and for critical reading 
of the manuscript.

Funding information: Work on mitoNEET by MPGC and CB was supported by the Fondation pour la Recherche Médicale (ING20101220983) and the Agence Nationale de la Recherche (ANR-13BSV8-0017-01).

\section{REFERENCES}

[1] Beinert H, Sands, RH. Biochem Biophys Res Commun 1960; 7:41-6.

[2] Beinert H, Holm RH, Munck E. Iron-sulfur clusters: nature's modular, multipurpose structures. Science 1997; 277:653-9.

[3] Fleischhacker AS, Kiley PJ. Iron-containing transcription factors and their roles as sensors. Curr Opin Chem Biol 2011; 15:335-41.

[4] Miller HK, Auerbuch V. Bacterial iron-sulfur cluster sensors in mammalian pathogens. Metallomics 2015; 7:943-56.

[5] Mettert EL, Kiley PJ. Fe-S proteins that regulate gene expression. Biochim Biophys Acta 2015; 1853:1284-93.

[6] Crack JC, Green J, Hutchings MI, Thomson AJ, Le Brun NE. Bacterial iron-sulfur regulatory proteins as biological sensor-switches. Antioxid Redox Signal 2012; 17:1215-31.

[7] Mortenson LE, Valentine RC, Carnahan JE. An electron transport factor from Clostridium pasteurianum. Biochem Biophys Res Commun 1962; 7:448-52.

[8] Johnson DC, Dean DR, Smith AD, Johnson MK. Structure, function, and formation of biological iron-sulfur clusters. Annu Rev Biochem 2005; 74:247-81.

[9] Meyer J. Iron-sulfur protein folds, iron-sulfur chemistry, and evolution. J Biol Inorg Chem 2008; 13:157-70.

[10] Beinert H. Iron-sulfur proteins: ancient structures, still full of surprises. J Biol Inorg Chem 2000; 5:2-15.

[11] Leggate EJ, Bill E, Essigke T, Ullmann GM, Hirst J. Formation and characterization of an all-ferrous Rieske cluster and stabilization of the [2Fe-2S] core by protonation. Proc Natl Acad Sci U S A 2004; 101:10913-

[12] Angove H, Yoo, SJ, Burgess, BK, Münck, E. J Am Chem Soc 1997; 119:8730-9731.

[13] Pandelia ME, Lanz ND, Booker SJ, Krebs C. Mossbauer spectroscopy of $\mathrm{Fe} / \mathrm{S}$ proteins. Biochim Biophys Acta 2015; 1853:1395-405.

[14] Lauble H, Stout CD. Steric and conformational features of the aconitase mechanism. Proteins 1995; 22:1-11.

[15] Shisler KA, Broderick JB. Emerging themes in radical SAM chemistry. Curr Opin Struct Biol 2012; 22:701-10.

[16] Reeve JN, Beckler GS, Cram DS, et al. A hydrogenase-linked gene in Methanobacterium thermoautotrophicum strain delta $\mathrm{H}$ encodes a polyferredoxin. Proc Natl Acad Sci U S A 1989; 86:3031-5.

[17] Lu J, Holmgren A. The thioredoxin superfamily in oxidative protein folding. Antioxid Redox Signal 2014; 21:457-70.

[18] Fugate CJ, Jarrett JT. Biotin synthase: insights into radical-mediated carbon-sulfur bond formation. Biochim Biophys Acta 2009; 1824:1213-22.

[19] Beilschmidt LK, Puccio HM. Mammalian Fe-S cluster biogenesis and its implication in disease. Biochimie 2014; 100:48-60.

[20] Ferecatu I, Gonçalves S, Golinelli-Cohen M-P, et al. The drug diabetes MitoNEET governs a novel trafficking pathway to rebuild an Fe-S cluster into cytosolic aconitase/Iron Regulatory Protein 1. J Biol Chem 2014; 289:28070-86

[21] Lukianova OA, David SS. A role for iron-sulfur clusters in DNA repair. Curr Opin Chem Biol 2005; 9:145-51.

[22] Boal AK, Yavin E, Barton JK. DNA repair glycosylases with a [4Fe4S] cluster: a redox cofactor for DNA-mediated charge transport? J Inorg Biochem 2007; 101:1913-21

[23] Fuss JO, Tsai CL, Ishida JP, Tainer JA. Emerging critical roles of Fe-S clusters in DNA replication and repair. Biochim Biophys Acta 2015; 1853:1253-71.

[24] Kimura S, Suzuki T. Iron-sulfur proteins responsible for RNA modifications. Biochim Biophys Acta 2015; 1853:1272-83.

[25] Anderson CP, Shen M, Eisenstein RS, Leibold EA. Mammalian iron metabolism and its control by iron regulatory proteins. Biochim Biophys Acta 2012; 1823:1468-83

[26] Crack JC, Green J, Thomson AJ, Le Brun NE. Iron-sulfur clusters as biological sensors: the chemistry of reactions with molecular oxygen and nitric oxide. Acc Chem Res 2014; 47:3196-205.

[27] Kobayashi K, Fujikawa M, Kozawa T. Oxidative stress sensing by the iron-sulfur cluster in the transcription factor, SoxR. J Inorg Biochem 2014;
133:87-91

[28] Kim J, Rees DC. Nitrogenase and biological nitrogen fixation. Biochemistry 1994; 33:389-97.

[29] Goldberg I, Nadler V, Hochman A. Mechanism of nitrogenase switchoff by oxygen. J Bacteriol 1987; 169:874-9.

[30] Robson RL. Characterization of an oxygen-stable nitrogenase complex isolated from Azotobacter chroococcum. Biochem J 1979; 181:569-75.

[31] Shethna YI, DerVartanian DV, Beinert H. Non heme (iron-sulfur) proteins of Azotobacter vinelandii. Biochem Biophys Res Commun 1968; 31:862-8.

[32] Bulen WA, LeComte JR. Nitrogenase complex and its components. Methods Enzymol 1972; 24:456-70.

[33] Moshiri F, Kim JW, Fu C, Maier RJ. The FeSII protein of Azotobacter vinelandii is not essential for aerobic nitrogen fixation, but confers significant protection to oxygen-mediated inactivation of nitrogenase in vitro and in vivo. Mol Microbiol 1994; 14:101-14.

[34] Maier RJ, Moshiri F. Role of the Azotobacter vinelandii nitrogenaseprotective shethna protein in preventing oxygen-mediated cell death. J Bacteriol 2000; 182:3854-7.

[35] Scherings G, Haaker H, Wassink H, Veeger C. On the formation of an oxygen-tolerant three-component nitrogenase complex from Azotobacter vinelandii. Eur J Biochem 1983; 135:591-9.

[36] Wang ZC, Burns A, Watt GD. Complex formation and O2 sensitivity of Azotobacter vinelandii nitrogenase and its component proteins. Biochemistry $1985 ; 24: 214-21$.

[37] Schlesier J, Rohde M, Gerhardt S, Einsle O. A Conformational Switch Triggers Nitrogenase Protection from Oxygen Damage by Shethna Protein II (FeSII). J Am Chem Soc 2016; 138:239-47.

[38] Ureta A, Nordlund S. Evidence for conformational protection of nitrogenase against oxygen in Gluconacetobacter diazotrophicus by a putative FeSII protein. J Bacteriol 2002; 184:5805-9.

[39] Lin J, Zhang L, Lai S, Ye K. Structure and molecular evolution of CDGSH iron-sulfur domains. PLoS One 2011; 6:e24790.

[40] Nechushtai R, Conlan AR, Harir Y, et al. Characterization of Arabidopsis NEET reveals an ancient role for NEET proteins in iron metabolism. Plant Cell 2012; 24:2139-54.

[41] Wiley SE, Murphy AN, Ross SA, van der Geer P, Dixon JE. MitoNEET is an iron-containing outer mitochondrial membrane protein that regulates oxidative capacity. Proc Natl Acad Sci U S A 2007; 104:5318-23.

[42] Tamir S, Paddock ML, Darash-Yahana-Baram M, et al. Structurefunction analysis of NEET proteins uncovers their role as key regulators of iron and ROS homeostasis in health and disease. Biochim Biophys Acta $2015 ; 1853: 1294-315$

[43] Kusminski CM, Holland WL, Sun K, et al. MitoNEET-driven alterations in adipocyte mitochondrial activity reveal a crucial adaptive process that preserves insulin sensitivity in obesity. Nat Med 2012; $18: 1539-49$.

[44] Landry AP, Ding H. Redox control of human mitochondrial outer membrane protein MitoNEET [2Fe-2S] clusters by biological thiols and hydrogen peroxide. J Biol Chem 2014; 289:4307-15.

[45] Sohn YS, Tamir S, Song L, et al. NAF-1 and mitoNEET are central to human breast cancer proliferation by maintaining mitochondrial homeostasis and promoting tumor growth. Proc Natl Acad Sci U S A 2013; 110:14676-81.

[46] Wiley SE, Andreyev AY, Divakaruni AS, et al. Wolfram Syndrome protein, Miner1, regulates sulphydryl redox status, the unfolded protein response, and Ca2+ homeostasis. EMBO Mol Med 2013; 5:904-18.

[47] Boucquey M, De Plaen E, Locker M, et al. Noxp20 and Noxp70, two new markers of early neuronal differentiation, detected in teratocarcinomaderived neuroectodermic precursor cells. J Neurochem 2006; 99:657-69.

[48] Chang NC, Nguyen M, Germain M, Shore GC. Antagonism of Beclin 1-dependent autophagy by BCL-2 at the endoplasmic reticulum requires NAF-1. EMBO J 2010; 29:606-18.

[49] Holt SH, Darash-Yahana M, Sohn YS, et al. Activation of apoptosis in NAF-1-deficient human epithelial breast cancer cells. J Cell Sci 2016; 129:155-65.

[50] Wang $\mathrm{CH}$, Chen $\mathrm{YF}$, Wu $\mathrm{CY}$, et al. Cisd2 modulates the differentiation and functioning of adipocytes by regulating intracellular Ca2+ homeostasis. Hum Mol Genet 2014; 23:4770-85.

[51] Chen YF, Kao CH, Chen YT, et al. Cisd2 deficiency drives premature aging and causes mitochondria-mediated defects in mice. Genes Dev 2009; 23:1183-94. 
[52] Lin CC, Chiang TH, Chen WJ, Sun YY, Lee YH, Lin MS. CISD2 serves a novel role as a suppressor of nitric oxide signalling and curcumin increases CISD2 expression in spinal cord injuries. Injury 2015; 46:234150 .

[53] Amr S, Heisey C, Zhang M, et al. A homozygous mutation in a novel zinc-finger protein, ERIS, is responsible for Wolfram syndrome 2. Am J Hum Genet 2007; 81:673-83

[54] Rondinelli M, Novara F, Calcaterra V, Zuffardi O, Genovese S. Wolfram syndrome 2: a novel CISD2 mutation identified in Italian siblings. Acta Diabetol 2014; 52:175-8

[55] Mozzillo E, Delvecchio M, Carella M, et al. A novel CISD2 intragenic deletion, optic neuropathy and platelet aggregation defect in Wolfram syndrome type 2. BMC Med Genet 2014; 15:88.

[56] Salem AF, Whitaker-Menezes D, Howell A, Sotgia F, Lisanti MP. Mitochondrial biogenesis in epithelial cancer cells promotes breast cancer tumor growth and confers autophagy resistance. Cell cycle 2012; 11:4174 80 .

[57] Wang L, Ouyang F, Liu X, et al. Overexpressed CISD2 has prognostic value in human gastric cancer and promotes gastric cancer cell proliferation and tumorigenesis via AKT signaling pathway. Oncotarget 2016; 7:3791805.

[58] Perez-Ramirez M, Hernandez-Jimenez AJ, Guerrero-Guerrero A, et al. Genomics and epigenetics: A study of ependymomas in pediatric patients. Clin Neurol Neurosurg 2016; 144:53-8.

[59] Hou X, Liu R, Ross S, Smart EJ, Zhu H, Gong W. Crystallographic studies of human MitoNEET. J Biol Chem 2007; 282:33242-6.

[60] Lin J, Zhou T, Ye K, Wang J. Crystal structure of human mitoNEET reveals distinct groups of iron sulfur proteins. Proc Natl Acad Sci U S A 2007; 104:14640-5.

[61] Paddock ML, Wiley SE, Axelrod HL, et al. MitoNEET is a uniquely folded $2 \mathrm{Fe} 2 \mathrm{~S}$ outer mitochondrial membrane protein stabilized by pioglitazone. Proc Natl Acad Sci U S A 2007; 104:14342-7.

[62] Wiley SE, Paddock ML, Abresch EC, et al. The outer mitochondrial membrane protein mitoNEET contains a novel redox-active $2 \mathrm{Fe}-2 \mathrm{~S}$ cluster. J Biol Chem 2007; 282:23745-9.

[63] Conlan AR, Paddock ML, Axelrod HL, et al. The novel 2Fe-2S outer mitochondrial protein mitoNEET displays conformational flexibility in its N-terminal cytoplasmic tethering domain. Acta Crystallogr Sect F Struct Biol Cryst Commun 2009; 65:654-9.

[64] Bak DW, Zuris JA, Paddock ML, Jennings PA, Elliott SJ. Redox characterization of the FeS protein MitoNEET and impact of thiazolidinedione drug binding. Biochemistry 2009; 48:10193-5.

[65] Tirrell TF, Paddock ML, Conlan AR, et al. Resonance Raman studies of the (His)(Cys)3 2Fe-2S cluster of MitoNEET: comparison to the (Cys) 4 mutant and implications of the effects of $\mathrm{pH}$ on the labile metal center. Biochemistry 2009; 48:4747-52.

[66] Golinelli-Cohen MP, Lescop E, Mons C, et al. Redox Control of the Human Iron-Sulfur Repair Protein MitoNEET Activity via its Iron-Sulfur Cluster. J Biol Chem 2016; 291:7583-93.

[67] Landry AP, Cheng Z, Ding H. Reduction of mitochondrial protein mitoNEET [2Fe-2S] clusters by human glutathione reductase. Free Radic Biol Med 2015; 81:119-27.

[68] Lipper CH, Paddock ML, Onuchic JN, Mittler R, Nechushtai R, Jennings PA. Cancer-Related NEET Proteins Transfer 2Fe-2S Clusters to Anamorsin, a Protein Required for Cytosolic Iron-Sulfur Cluster Biogenesis. PLoS One 2016; 10:e0139699.

[69] Zuris JA, Harir Y, Conlan AR, et al. Facile transfer of [2Fe-2S] clusters from the diabetes drug target mitoNEET to an apo-acceptor protein. Proc Natl Acad Sci U S A 2011; 108:13047-52.

[70] Dicus MM, Conlan A, Nechushtai R, et al. Binding of histidine in the (Cys)3(His)1-coordinated [2Fe-2S] cluster of human mitoNEET. J Am Chem Soc 2010; 132:2037-49.

[71] Tan G, Liu D, Pan F, et al. His-87 ligand in mitoNEET is crucial for the transfer of iron sulfur clusters from mitochondria to cytosolic aconitase. Biochem Biophys Res Commun 2016; 470:226-32.

[72] Wallace SS. Base excision repair: a critical player in many games. DNA Repair (Amst) 2014; 19:14-26.

[73] Cunningham RP, Asahara H, Bank JF, et al. Endonuclease III is an iron-sulfur protein. Biochemistry 1989; 28:4450-5.

[74] Thayer MM, Ahern H, Xing D, Cunningham RP, Tainer JA. Novel DNA binding motifs in the DNA repair enzyme endonuclease III crystal structure. EMBO J 1995; 14:4108-20.

[75] Guan Y, Manuel RC, Arvai AS, et al. MutY catalytic core, mutant and bound adenine structures define specificity for DNA repair enzyme superfamily. Nat Struct Biol 1998; 5:1058-64.

[76] Michaels ML, Pham L, Nghiem Y, Cruz C, Miller JH. MutY, an adenine glycosylase active on G-A mispairs, has homology to endonuclease III. Nucleic Acids Res 1990; 18:3841-5.

[77] Piersen CE, Prince MA, Augustine ML, Dodson ML, Lloyd RS. Purification and cloning of Micrococcus luteus ultraviolet endonuclease, an $\mathrm{N}$-glycosylase/abasic lyase that proceeds via an imino enzyme-DNA intermediate. J Biol Chem 1995; 270:23475-84

[78] Horst JP, Fritz HJ. Counteracting the mutagenic effect of hydrolytic deamination of DNA 5-methylcytosine residues at high temperature: DNA mismatch N-glycosylase Mig.Mth of the thermophilic archaeon Methanobacterium thermoautotrophicum THF. EMBO J 1996; 15:5459-69. [79] Begley TJ, Haas BJ, Noel J, Shekhtman A, Williams WA, Cunningham RP. A new member of the endonuclease III family of DNA repair enzymes that removes methylated purines from DNA. Curr Biol 1999; 9:653-6.

[80] Hinks JA, Evans MC, De Miguel Y, Sartori AA, Jiricny J, Pearl LH. An iron-sulfur cluster in the family 4 uracil-DNA glycosylases. J Biol Chem 2002; 277:16936-40

[81] Pope MA, Chmiel NH, David SS. Insight into the functional consequences of hMYH variants associated with colorectal cancer: distinct differences in the adenine glycosylase activity and the response to AP endonucleases of Y150C and G365D murine MYH. DNA Repair (Amst) 2005; 4:315-25.

[82] Engstrom LM, Brinkmeyer MK, Ha Y, et al. A zinc linchpin motif in the MUTYH glycosylase interdomain connector is required for efficient repair of DNA damage. J Am Chem Soc 2014; 136:7829-32.

[83] Luncsford PJ, Chang DY, Shi G, et al. A structural hinge in eukaryotic MutY homologues mediates catalytic activity and Rad9-Rad1-Hus1 checkpoint complex interactions. J Mol Biol 2010; 403:351-70.

[84] Aspinwall R, Rothwell DG, Roldan-Arjona T, et al. Cloning and characterization of a functional human homolog of Escherichia coli endonuclease III. Proc Natl Acad Sci U S A 1997; 94:109-14.

[85] Porello SL, Cannon MJ, David SS. A substrate recognition role for the [4Fe-4S]2+ cluster of the DNA repair glycosylase MutY. Biochemistry $1998 ; 37: 6465-75$

[86] Golinelli MP, Chmiel NH, David SS. Site-directed mutagenesis of the cysteine ligands to the $[4 \mathrm{Fe}-4 \mathrm{~S}]$ cluster of Escherichia coli MutY. Biochemistry 1999; 38:6997-7007.

[87] Kuo CF, McRee DE, Fisher CL, O'Handley SF, Cunningham RP, Tainer JA. Atomic structure of the DNA repair [4Fe-4S] enzyme endonuclease III. Science 1992; 258:434-40.

[88] Hoseki J, Okamoto A, Masui R, et al. Crystal structure of a family 4 uracil-DNA glycosylase from Thermus thermophilus HB8. J Mol Biol 2003; 333:515-26

[89] Fromme JC, Verdine GL. Structure of a trapped endonuclease IIIDNA covalent intermediate. EMBO J 2003; 22:3461-71.

[90] Fromme JC, Banerjee A, Huang SJ, Verdine GL. Structural basis for removal of adenine mispaired with 8-oxoguanine by MutY adenine DNA glycosylase. Nature 2004; 427:652-6.

[91] Kosaka H, Hoseki J, Nakagawa N, Kuramitsu S, Masui R. Crystal structure of family 5 uracil-DNA glycosylase bound to DNA. J Mol Biol 2007; 373:839-50

[92] Engstrom LM, Partington OA, David SS. An iron-sulfur cluster loop motif in the Archaeoglobus fulgidus uracil-DNA glycosylase mediates efficient uracil recognition and removal. Biochemistry 2012; 51:5187-97.

[93] Chepanoske CL, Golinelli MP, Williams SD, David SS. Positively charged residues within the iron-sulfur cluster loop of E. coli MutY participate in damage recognition and removal. Arch Biochem Biophys 2000; 380:11-9.

[94] Trasvina-Arenas CH, Lopez-Castillo LM, Sanchez-Sandoval E, Brieba LG. Dispensability of the [4Fe-4S] cluster in novel homologues of adenine glycosylase MutY. FEBS J 2016; 283:521-40.

[95] Boon EM, Livingston AL, Chmiel NH, David SS, Barton JK. DNAmediated charge transport for DNA repair. Proc Natl Acad Sci U S A 2003; 100:12543-7.

[96] Boal AK, Yavin E, Lukianova OA, O'Shea VL, David SS, Barton JK. DNA-bound redox activity of DNA repair glycosylases containing [4Fe4S] clusters. Biochemistry 2005; 44:8397-407.

[97] Yavin E, Boal AK, Stemp ED, et al. Protein-DNA charge transport: redox activation of a DNA repair protein by guanine radical. Proc Natl Acad Sci U S A 2005; 102:3546-51. 
[98] Yavin E, Stemp ED, O'Shea V L, David SS, Barton JK. Electron trap for DNA-bound repair enzymes: a strategy for DNA-mediated signaling. Proc Natl Acad Sci U S A 2006; 103:3610-4.

[99] Francis AW, David SS. Escherichia coli MutY and Fpg utilize a processive mechanism for target location. Biochemistry 2003; 42:801-10.

[100] Boal AK, Genereux JC, Sontz PA, Gralnick JA, Newman DK, Barton JK. Redox signaling between DNA repair proteins for efficient lesion detection. Proc Natl Acad Sci U S A 2009; 106:15237-42.

[101] Romano CA, Sontz PA, Barton JK. Mutants of the base excision repair glycosylase, endonuclease III: DNA charge transport as a first step in lesion detection. Biochemistry 2011; 50:6133-45.

[102] Rudolf J, Makrantoni V, Ingledew WJ, Stark MJ, White MF. The DNA repair helicases XPD and FancJ have essential iron-sulfur domains. Mol Cell 2006; 23:801-8.

[103] Pugh RA, Honda M, Leesley H, et al. The iron-containing domain is essential in Rad3 helicases for coupling of ATP hydrolysis to DNA translocation and for targeting the helicase to the single-stranded DNAdouble-stranded DNA junction. J Biol Chem 2008; 283:1732-43.

[104] Ren B, Duan X, Ding H. Redox control of the DNA damageinducible protein DinG helicase activity via its iron-sulfur cluster. J Biol Chem 2009; 284:4829-35.

[105] Landry AP, Ding H. The N-terminal domain of human DNA helicase Rtel1 contains a redox active iron-sulfur cluster. Biomed Res Int 2014; 2014:285791

[106] Yeeles JT, Cammack R, Dillingham MS. An iron-sulfur cluster is essential for the binding of broken DNA by AddAB-type helicasenucleases. J Biol Chem 2009; 284:7746-55.

[107] Pokharel S, Campbell JL. Cross talk between the nuclease and helicase activities of Dna2: role of an essential iron-sulfur cluster domain. Nucleic Acids Res 2012; 40:7821-30.

[108] Liu H, Rudolf J, Johnson KA, et al. Structure of the DNA repair helicase XPD. Cell 2008; 133:801-12.

[109] Wolski SC, Kuper J, Hanzelmann P, et al. Crystal structure of the FeS cluster-containing nucleotide excision repair helicase XPD. PLoS Biol 2008; 6:e149.

[110] Fan L, Fuss JO, Cheng QJ, et al. XPD helicase structures and activities: insights into the cancer and aging phenotypes from XPD mutations. Cell 2008; 133:789-800.

[111] Constantinescu-Aruxandei D, Petrovic-Stojanovska B, Penedo JC, White MF, Naismith JH. Mechanism of DNA loading by the DNA repair helicase XPD. Nucleic Acids Res 2016; 44:2806-15.

[112] Saikrishnan K, Yeeles JT, Gilhooly NS, Krajewski WW, Dillingham MS, Wigley DB. Insights into Chi recognition from the structure of an AddAB-type helicase-nuclease complex. EMBO J 2012; 31:1568-78.

[113] Wolski SC, Kuper J, Kisker C. The XPD helicase: XPanDing archaeal XPD structures to get a grip on human DNA repair. Biol Chem 2010; 391:761-5

[114] Mui TP, Fuss JO, Ishida JP, Tainer JA, Barton JK. ATP-stimulated, DNA-mediated redox signaling by XPD, a DNA repair and transcription helicase. J Am Chem Soc 2011; 133:16378-81.

[115] Sontz PA, Mui TP, Fuss JO, Tainer JA, Barton JK. DNA charge transport as a first step in coordinating the detection of lesions by repair proteins. Proc Natl Acad Sci U S A 2012; 109:1856-61.

[116] Grodick MA. DNA-mediated charge transport signaling within the cell. Dissertation (Ph D) California Institute of Technology. 2016.

[117] Grodick MA, Segal HM, Zwang TJ, Barton JK. DNA-mediated signaling by proteins with $4 \mathrm{Fe}-4 \mathrm{~S}$ clusters is necessary for genomic integrity. J Am Chem Soc 2014; 136:6470-8.

[118] Arnold AR, Grodick MA, Barton JK. DNA Charge Transport: from Chemical Principles to the Cell. Cell Chem Biol 2016; 23:183-97.

[119] Netz DJ, Stith CM, Stumpfig M, et al. Eukaryotic DNA polymerases require an iron-sulfur cluster for the formation of active complexes. Nat Chem Biol 2011; 8:125-32

[120] Weiner BE, Huang H, Dattilo BM, Nilges MJ, Fanning E, Chazin WJ. An iron-sulfur cluster in the C-terminal domain of the p58 subunit of human DNA primase. J Biol Chem 2007; 282:33444-51.

[121] Holt ME, O'Brien E, Salay L, et al. Cracking Open a Molecular Calculator: DNA Charge Transport and Primase. Biophysical Journal 2016; 110:p21a.

[122] Andujar E, Hernaez MJ, Kaschabek SR, Reineke W, Santero E. Identification of an extradiol dioxygenase involved in tetralin biodegradation: gene sequence analysis and purification and characterization of the gene product. J Bacteriol 2000; 182:789-95.
[123] Moreno-Ruiz E, Hernaez MJ, Martinez-Perez O, Santero E. Identification and functional characterization of Sphingomonas macrogolitabida strain TFA genes involved in the first two steps of the tetralin catabolic pathway. J Bacteriol 2003; 185:2026-30.

[124] Martinez-Perez O, Moreno-Ruiz E, Floriano B, Santero E. Regulation of tetralin biodegradation and identification of genes essential for expression of thn operons. J Bacteriol 2004; 186:6101-9.

[125] Ledesma-Garcia L, Rivas-Marin E, Floriano B, et al. ThnY is a ferredoxin reductase-like iron-sulfur flavoprotein that has evolved to function as a regulator of tetralin biodegradation gene expression. J Biol Chem 2011; 286:1709-18.

[126] Lopez-Sanchez A, Floriano B, Andujar E, Hernaez MJ, Santero E. Tetralin-induced and ThnR-regulated aldehyde dehydrogenase and betaoxidation genes in Sphingomonas macrogolitabida strain TFA. Appl Environ Microbiol 2010; 76:110-8.

[127] Ledesma-Garcia L, Reyes-Ramirez F, Santero E. The ferredoxin ThnA3 negatively regulates tetralin biodegradation gene expression via ThnY, a ferredoxin reductase that functions as a regulator of the catabolic pathway. PLoS One 2013; 8:e73910.

[128] Martinez-Perez O, Lopez-Sanchez A, Reyes-Ramirez F, Floriano B, Santero E. Integrated response to inducers by communication between a catabolic pathway and its regulatory system. J Bacteriol 2007; 189:376875.

[129] Ledesma-Garcia L, Sanchez-Azqueta A, Medina M, Reyes-Ramirez F, Santero E. Redox proteins of hydroxylating bacterial dioxygenases establish a regulatory cascade that prevents gratuitous induction of tetralin biodegradation genes. Sci Rep 2016; 6:23848.

[130] Salazar ME, Laub MT. Temporal and evolutionary dynamics of twocomponent signaling pathways. Curr Opin Microbiol 2015; 24:7-14.

[131] Taabazuing CY, Hangasky JA, Knapp MJ. Oxygen sensing strategies in mammals and bacteria. J Inorg Biochem 2014; 133:63-72.

[132] Somerville GA, Proctor RA. At the crossroads of bacterial metabolism and virulence factor synthesis in Staphylococci. Microbiol Mol Biol Rev 2009; 73:233-48

[133] Hall JW, Ji Y. Sensing and Adapting to Anaerobic Conditions by Staphylococcus aureus. Adv Appl Microbiol 2013; 84:1-25.

[134] Sun J, Zheng L, Landwehr C, Yang J, Ji Y. Identification of a novel essential two-component signal transduction system, YhcSR, in Staphylococcus aureus. J Bacteriol 2005; 187:7876-80.

[135] Hall JW, Yang J, Guo H, Ji Y. The AirSR two-component system contributes to Staphylococcus aureus survival in human blood and transcriptionally regulates sspABC operon. Front Microbiol 2015; 6:682.

[136] Sun F, Ji Q, Jones MB, et al. AirSR, a [2Fe-2S] cluster-containing two-component system, mediates global oxygen sensing and redox signaling in Staphylococcus aureus. J Am Chem Soc 2012; 134:305-14.

[137] Yan M, Yu C, Yang J, Ji Y. The essential two-component system YhcSR is involved in regulation of the nitrate respiratory pathway of Staphylococcus aureus. J Bacteriol 2011; 193:1799-805.

[138] Sun H, Yang Y, Xue T, Sun B. Modulation of cell wall synthesis and susceptibility to vancomycin by the two-component system AirSR in Staphylococcus aureus NCTC8325. BMC Microbiol 2013; 13:286.

[139] Hall JW, Yang J, Guo H, Ji Y. The Staphylococcus aureus AirSR Two-Component System Mediates Reactive Oxygen Species Resistance via Transcriptional Regulation of Staphyloxanthin Production. Infect Immun 2016 DOI:10.1128/IAI.00838-16.

[140] Wu J, Weiss B. Two divergently transcribed genes, soxR and soxS, control a superoxide response regulon of Escherichia coli. J Bacteriol 1991; 173:2864-71.

[141] Amabile-Cuevas CF, Demple B. Molecular characterization of the soxRS genes of Escherichia coli: two genes control a superoxide stress regulon. Nucleic Acids Res 1991; 19:4479-84.

[142] Pomposiello PJ, Demple B. Identification of SoxS-regulated genes in Salmonella enterica serovar typhimurium. J Bacteriol 2000; 182:23-9.

[143] Blanchard JL, Wholey WY, Conlon EM, Pomposiello PJ. Rapid changes in gene expression dynamics in response to superoxide reveal SoxRS-dependent and independent transcriptional networks. PLoS One 2007; 2:e1186.

[144] Gu M, Imlay JA. The SoxRS response of Escherichia coli is directly activated by redox-cycling drugs rather than by superoxide. Mol Microbiol 2011; 79:1136-50

[145] Nunoshiba T, Hidalgo E, Amabile Cuevas CF, Demple B. Two-stage control of an oxidative stress regulon: the Escherichia coli SoxR protein triggers redox-inducible expression of the soxS regulatory gene. J Bacteriol 
1992; 174:6054-60.

[146] Wu J, Weiss B. Two-stage induction of the soxRS (superoxide response) regulon of Escherichia coli. J Bacteriol 1992; 174:3915-20.

[147] Palma M, Zurita J, Ferreras JA, et al. Pseudomonas aeruginosa SoxR does not conform to the archetypal paradigm for SoxR-dependent regulation of the bacterial oxidative stress adaptive response. Infect Immun 2005; 73:2958-66.

[148] Dietrich LE, Teal TK, Price-Whelan A, Newman DK. Redox-active antibiotics control gene expression and community behavior in divergent bacteria. Science 2008; 321:1203-6.

[149] Mahavihakanont A, Charoenlap N, Namchaiw P, et al. Novel roles of SoxR, a transcriptional regulator from Xanthomonas campestris, in sensing redox-cycling drugs and regulating a protective gene that have overall implications for bacterial stress physiology and virulence on a host plant. J Bacteriol 2012; 194:209-17.

[150] Burbank L, Roper MC. OxyR and SoxR modulate the inducible oxidative stress response and are implicated during different stages of infection for the bacterial phytopathogen Pantoea stewartii subsp. stewartii. Mol Plant Microbe Interact 27:479-90.

[151] Naseer N, Shapiro JA, Chander M. RNA-Seq analysis reveals a sixgene SoxR regulon in Streptomyces coelicolor. PLoS One 2014; 9:e106181

[152] Hidalgo E, Demple B. An iron-sulfur center essential for transcriptional activation by the redox-sensing SoxR protein. EMBO J 1994; 13:138-46.

[153] Wu J, Dunham WR, Weiss B. Overproduction and physical characterization of SoxR, a $[2 \mathrm{Fe}-2 \mathrm{~S}]$ protein that governs an oxidative response regulon in Escherichia coli. J Biol Chem 1995; 270:10323-7.

[154] Watanabe S, Kita A, Kobayashi K, Miki K. Crystal structure of the [2Fe-2S] oxidative-stress sensor SoxR bound to DNA. Proc Natl Acad Sci U S A 2008; 105:4121-6.

[155] Gaudu P, Weiss B. SoxR, a [2Fe-2S] transcription factor, is active only in its oxidized form. Proc Natl Acad Sci U S A 1996; 93:10094-8.

[156] Ding H, Hidalgo E, Demple B. The redox state of the [2Fe-2S] clusters in SoxR protein regulates its activity as a transcription factor. J Biol Chem 1996; 271:33173-5.

[157] Ding H, Demple B. In vivo kinetics of a redox-regulated transcriptional switch. Proc Natl Acad Sci U S A 1997; 94:8445-9.

[158] Gorodetsky AA, Dietrich LE, Lee PE, Demple B, Newman DK, Barton JK. DNA binding shifts the redox potential of the transcription factor SoxR. Proc Natl Acad Sci U S A 2008; 105:3684-9.
[159] Sheplock R, Recinos DA, Mackow N, Dietrich LE, Chander M. Species-specific residues calibrate SoxR sensitivity to redox-active molecules. Mol Microbiol 2013 87:368-81.

[160] Lee PE, Demple B, Barton JK. DNA-mediated redox signaling for transcriptional activation of SoxR. Proc Natl Acad Sci U S A 2009; 106:13164-8.

[161] Ding H, Demple B. Direct nitric oxide signal transduction via nitrosylation of iron-sulfur centers in the SoxR transcription activator. Proc Natl Acad Sci U S A 2000; 97:5146-50.

[162] Fujikawa M, Kobayashi K, Kozawa T. Mechanistic studies on formation of the dinitrosyl iron complex of the $[2 \mathrm{Fe}-2 \mathrm{~S}]$ cluster of SoxR protein. J Biochem 2014; 156:163-72.

[163] Lo FC, Chen CL, Lee CM, et al. A study of NO trafficking from dinitrosyl-iron complexes to the recombinant E. coli transcriptional factor SoxR. J Biol Inorg Chem 2008; 13:961-72.

[164] Kobayashi K, Mizuno M, Fujikawa M, Mizutani Y. Protein conformational changes of the oxidative stress sensor, SoxR, upon redox changes of the $[2 \mathrm{Fe}-2 \mathrm{~S}]$ cluster probed with ultraviolet resonance Raman spectroscopy. Biochemistry 2011; 50:9468-74.

[165] Fujikawa M, Kobayashi K, Kozawa T. Redox-dependent DNA distortion in a SoxR protein-promoter complex studied using fluorescent probes. J Biochem 2015; 157:389-97.

[166] Hidalgo E, Bollinger JM, Jr., Bradley TM, Walsh CT, Demple B. Binuclear $[2 \mathrm{Fe}-2 \mathrm{~S}]$ clusters in the Escherichia coli SoxR protein and role of the metal centers in transcription. J Biol Chem 1995; 270:20908-14.

[167] Hidalgo E, Demple B. Spacing of promoter elements regulates the basal expression of the soxS gene and converts SoxR from a transcriptional activator into a repressor. EMBO J 1997; 16:1056-65.

[168] Koo MS, Lee JH, Rah SY, et al. A reducing system of the superoxide sensor SoxR in Escherichia coli. EMBO J 2003; 22:2614-22.

[169] Griffith KL, Shah IM, Wolf RE, Jr. Proteolytic degradation of Escherichia coli transcription activators SoxS and MarA as the mechanism for reversing the induction of the superoxide (SoxRS) and multiple antibiotic resistance (Mar) regulons. Mol Microbiol 2004; 51:1801-16.

[170] Munnoch JT, Martinez MT, Svistunenko DA, Crack JC, Le Brun NE, Hutchings MI. Characterization of a putative NsrR homologue in Streptomyces venezuelae reveals a new member of the Rrf2 superfamily. Sci Rep 2016; 6:31597.

\section{FIGURE LEGENDS}

Figure 1. Protection of bacterial nitrogenase by oxidized FeSII protein. Composed of two Fe-S cluster-containing proteins (Fe and MoFe proteins), nitrogenase can be irreversibly inactivated by oxygen due to cluster oxidation. FeSII protein is involved in a pathway to protect nitrogenase against oxidative damage. In oxidative conditions, the $[2 \mathrm{Fe}-2 \mathrm{~S}]$ cluster of FeSII becomes oxidized. This change in the redox state of the cluster induces a major conformational change ("open conformation") that allows FeSII to form a protective but inactive complex with nitrogenase. After stress relief, FeSII returns to its reduced form ("closed conformation"), the complex dissociates, and nitrogenase activity is restored.

Figure 2. Fe-S cluster repair process of cytosolic aconitase/IRP1 by mitoNEET after oxidative stress. Under physiological redox conditions, mitoNEET is believed to accommodate a very stable [2Fe$2 \mathrm{~S}]^{+}$cluster, and the cytosolic aconitase/IRP1 assembles a redox sensitive [4Fe-4S] cluster, which is essential for aconitase activity. When cells are exposed to an oxidative or nitrosative stress, the [4Fe-4S] is completely disassembled revealing the IRP1 regulatory function. At the same time, the mitoNEET $[2 \mathrm{Fe}-2 \mathrm{~S}]$ cluster is oxidized ( +2 state). Upon cessation of oxidative stress, mitoNEET $[2 \mathrm{Fe}-2 \mathrm{~S}]^{2+}$ transfers its clusters to apo-IRP1, which is converted back into aconitase. Unfolded apo-mitoNEET might be recycled into holo-mitoNEET through the iron-sulfur cluster (ISC) assembly machinery, so as to repeat the steps described above. 
Figure 3. Search for DNA lesions by DNA repair proteins using their Fe-S clusters and DNAmediated charge transfer. A reduced $(2+$ state) DNA repair enzyme (BER glycosylase or helicase) loosely binds DNA (step 1). After transfer of one electron to a highly oxidizing guanine cation radical, the oxidized form (3+ state) tightly binds DNA (step 2$)$. Then, a second DNA repair enzyme of similar redox potential (2+ state) loosely binds to DNA (step 3). If DNA is intact between the two proteins (in the absence of DNA damage, step 4), the first enzyme can receive one electron (reduction of the first enzyme, $2+$ state) from the second one via DNA-mediated charge transfer and dissociates from DNA. If DNA is damaged between the two enzymes, they cannot exchange electrons (in the presence of damage to DNA, step 4). The second enzyme then transfers its electron to another enzyme localized in the distal side of the lesion (step 5). Both enzymes are oxidized (3+ state), bind DNA efficiently, and can slide along DNA to find and repair the lesion.

Figure 4. Regulation by ThnY of the catabolic pathway dedicated to the biodegradation of tetralin in Sphingomonas macrogolitabida. Biodegradation of tetralin is performed by the dioxygenase ThnA1/ThnA2, which receives electrons from $\mathrm{NAD}(\mathrm{P}) \mathrm{H}$ via the ferredoxin reductase ThnA4 and the ferredoxin ThnA3. (1) In the presence of tetralin substrate, ThnA3 is mostly oxidized. The Fe-S clustercontaining ThnY remains oxidized, binds to ThnR, and the transcription of thn genes is activated. (2) In absence of tetralin, ThnA3 is reduced and transfers electrons to ThnY (accumulation of reduced ThnY). Therefore, ThnR unable to form a complex with reduced ThnY does not induce the transcription of thn genes.

Figure 5. Regulation of Staphylococcus aureus virulence by the kinase AirS. Under anaerobic conditions, the [2Fe-2S]-containing AirS is reduced and its kinase activity is low. In moderate oxidative conditions, the AirS Fe-S cluster is oxidized and exhibits efficient kinase activity. It phosphorylates AirR, a major transcriptional regulator of more than 350 genes involved in bacterial survival and virulence. However, under conditions of prolonged exposure to oxygen, ROS or RNS, the AirS cluster is lost (apoform due to oxygen exposure or ROS) or modified (DNIC-modified form due to RNS), and AirS has no kinase activity.

Figure 6. SoxR, a bacterial two-stage control system for cell survival under physiological stress. The redox-sensor SoxR is a homodimer, which holds one [2Fe-2S] cluster per monomer. During normal aerobic growth, SoxR [2Fe-2S] clusters are reduced and the protein binds a specific promoter region of its target gene sox $S$ and inactivates its transcription. During oxidative stress, the redox cycling compounds produced cause oxidation of SoxR [2Fe-2S] clusters, resulting in a conformational change of the protein. The active oxidized form of SoxR remodels the conformation of the soxS promoter in a way that allows RNA polymerase to initiate transcription of SoxS. The increased levels of SoxS protein then activate the various soxRS regulon genes.

Figure 7. Fe-S cluster-containing redox switches are key components of efficient cellular responses to change in cellular environments. 

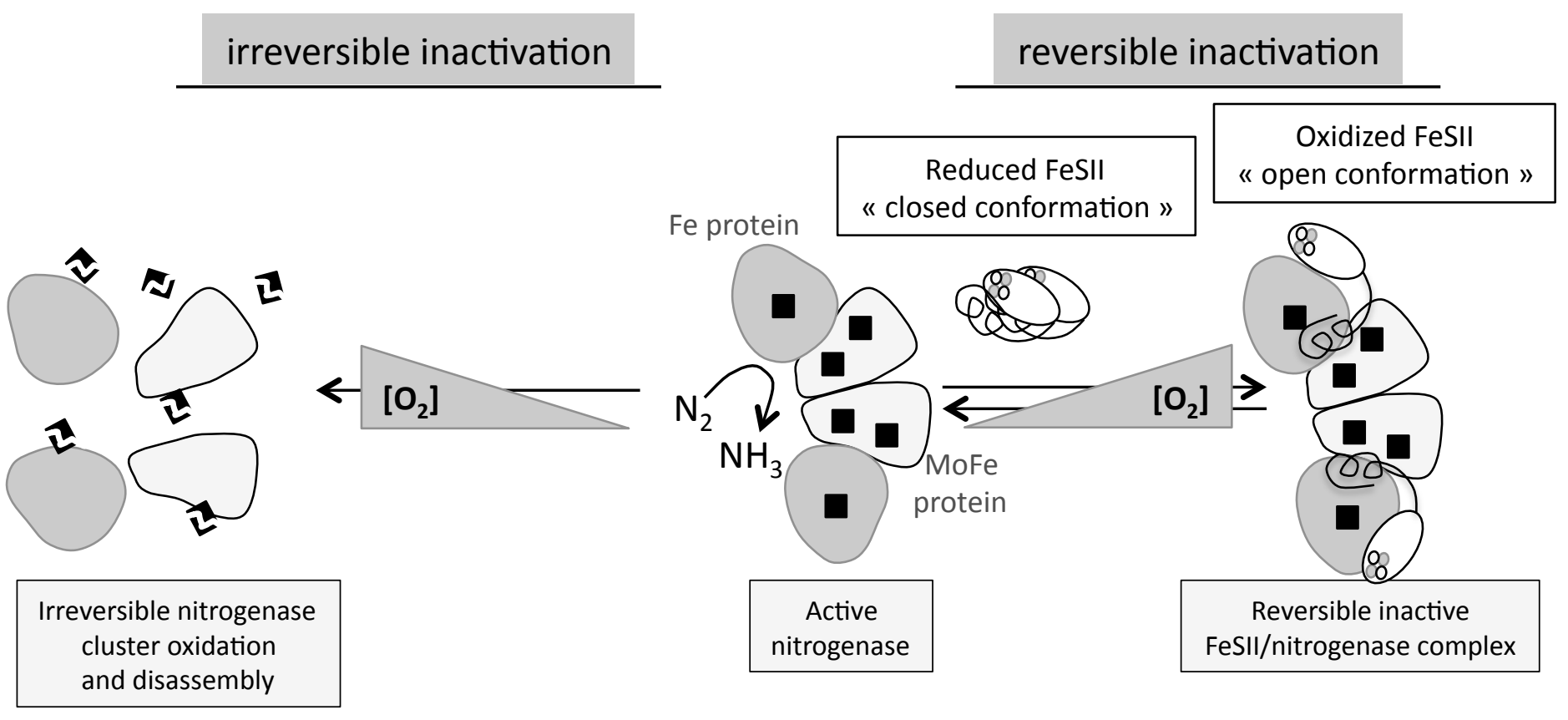

Figure 1 


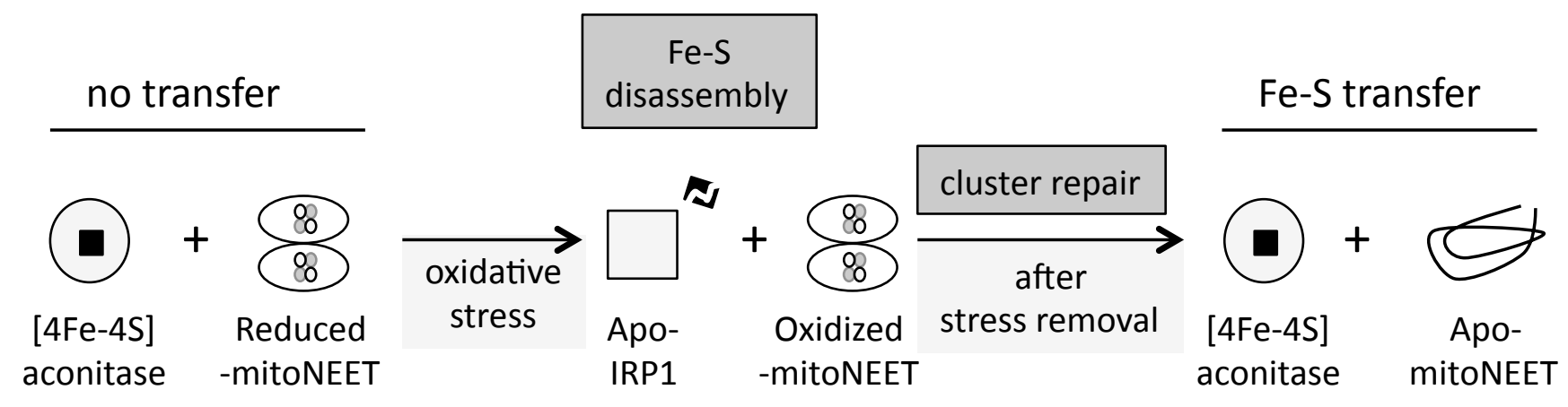

Figure 2 

(1) $\sum^{2+3}$

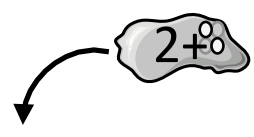

(1)

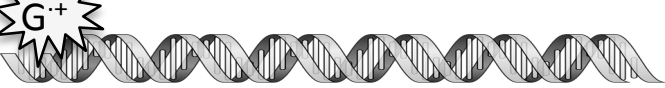

(2) $\mathrm{s}^{2}+3+5$

(3) 3+0 200

(4)

\section{$2+8$}

(5)

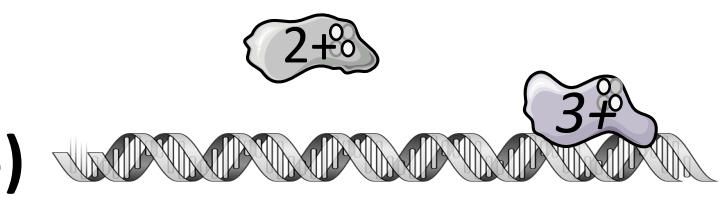

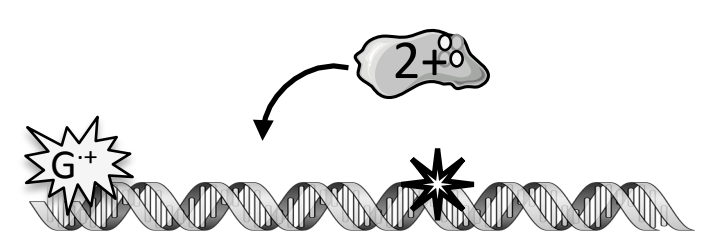
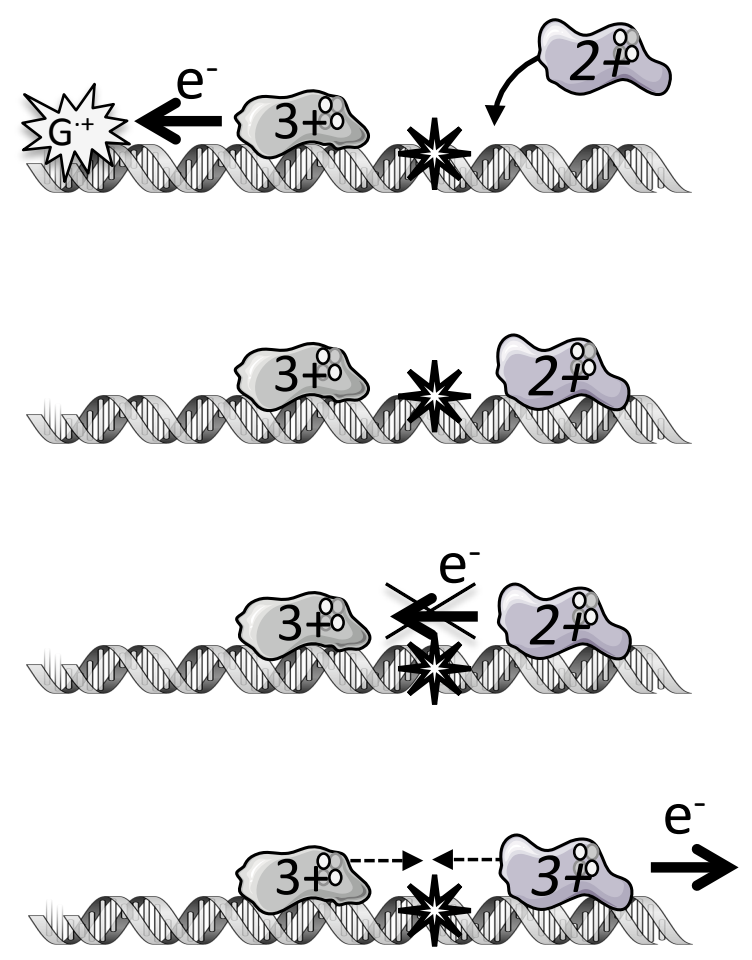

Figure 3 
(1) In the presence of tetralin
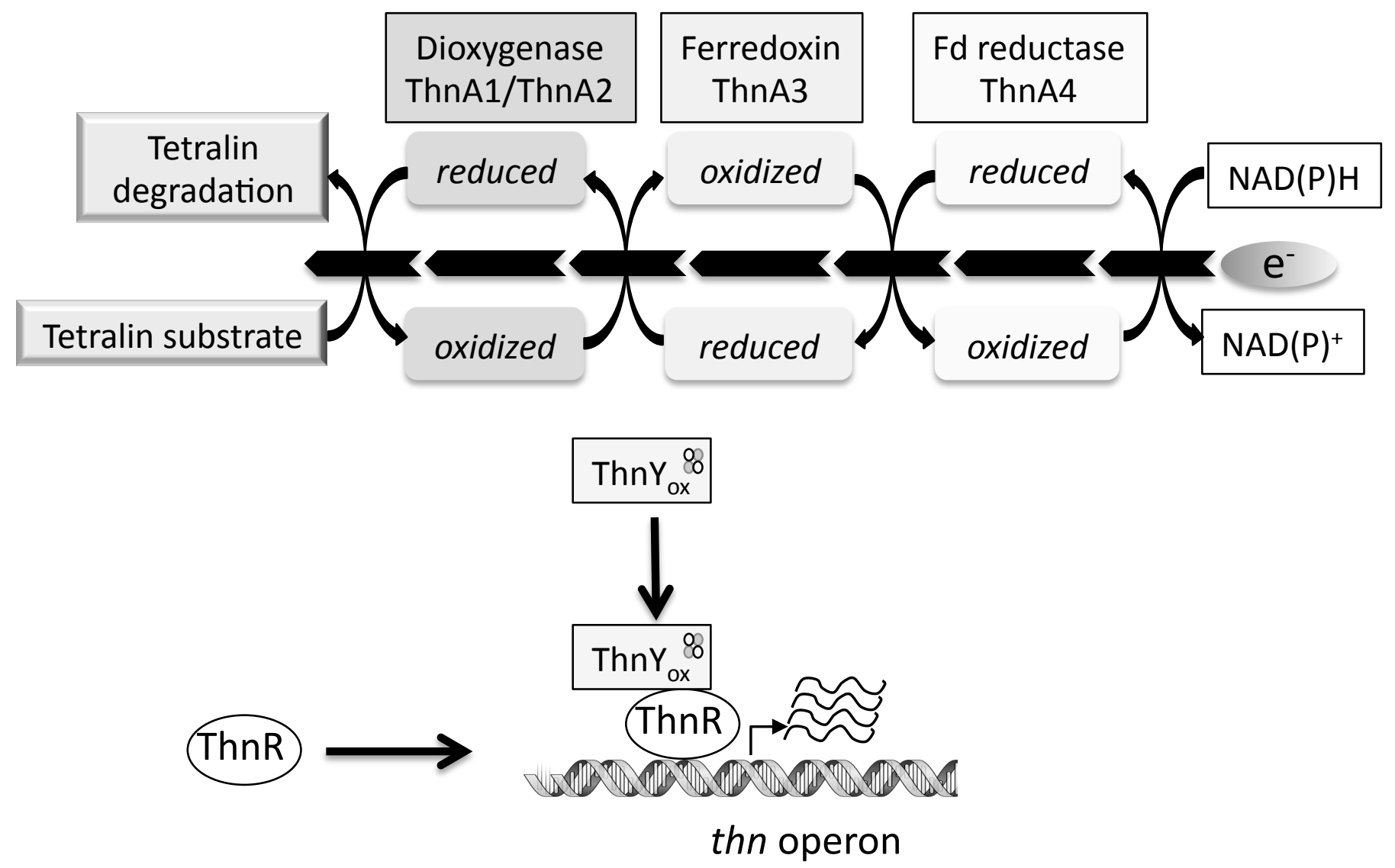

(2) In the absence of tetralin
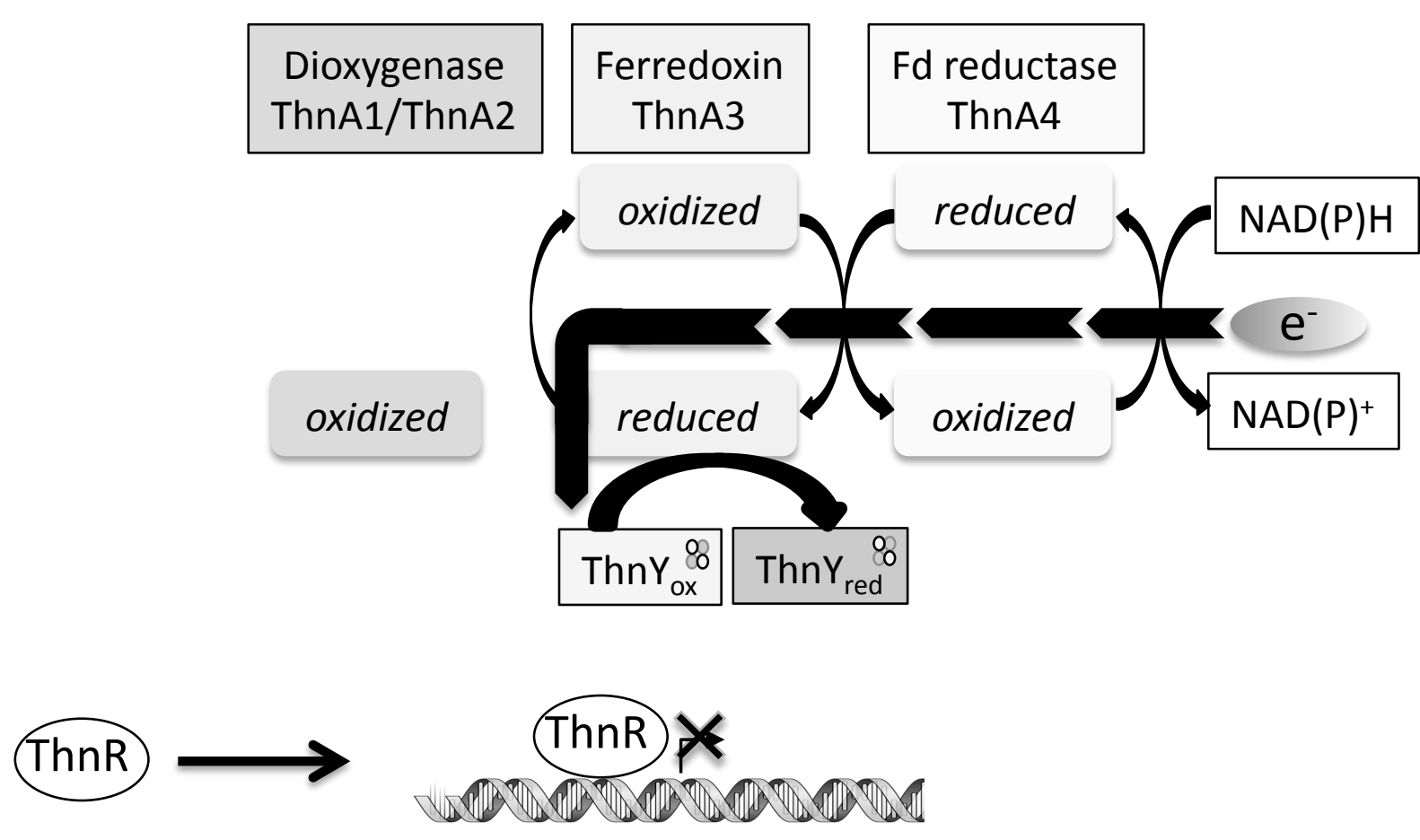

thn operon

Figure 4 


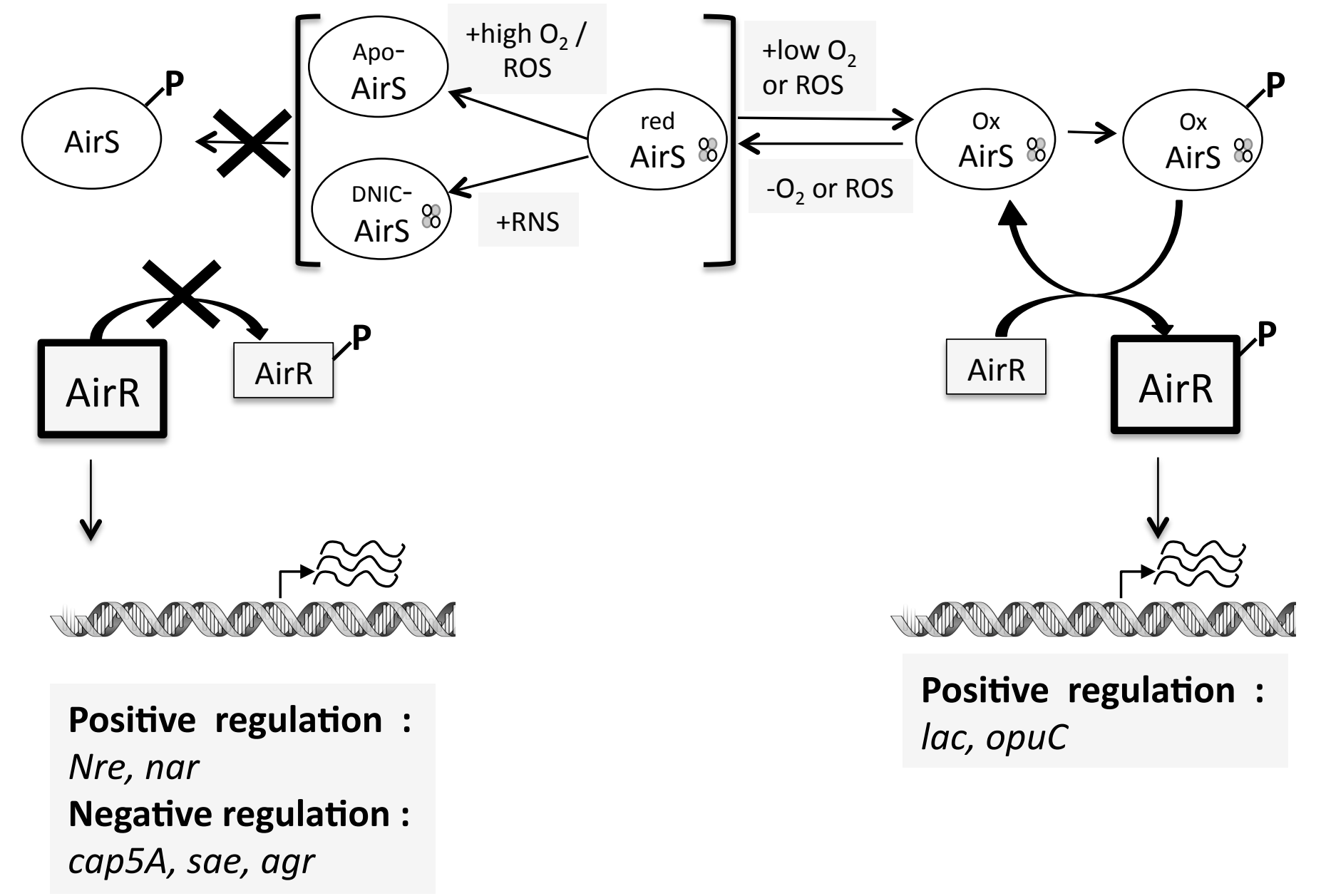

Figure 5 


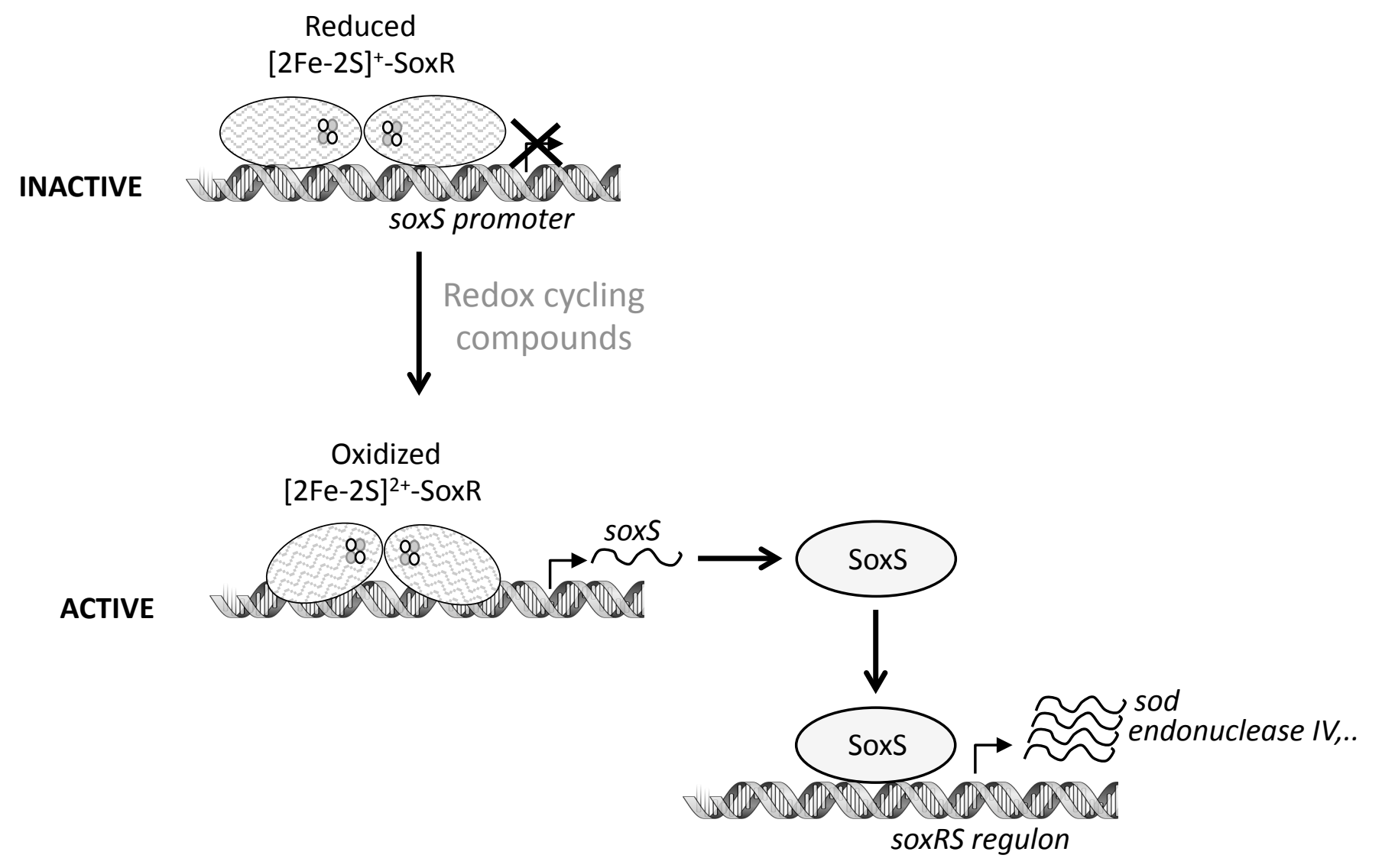

Figure 6 


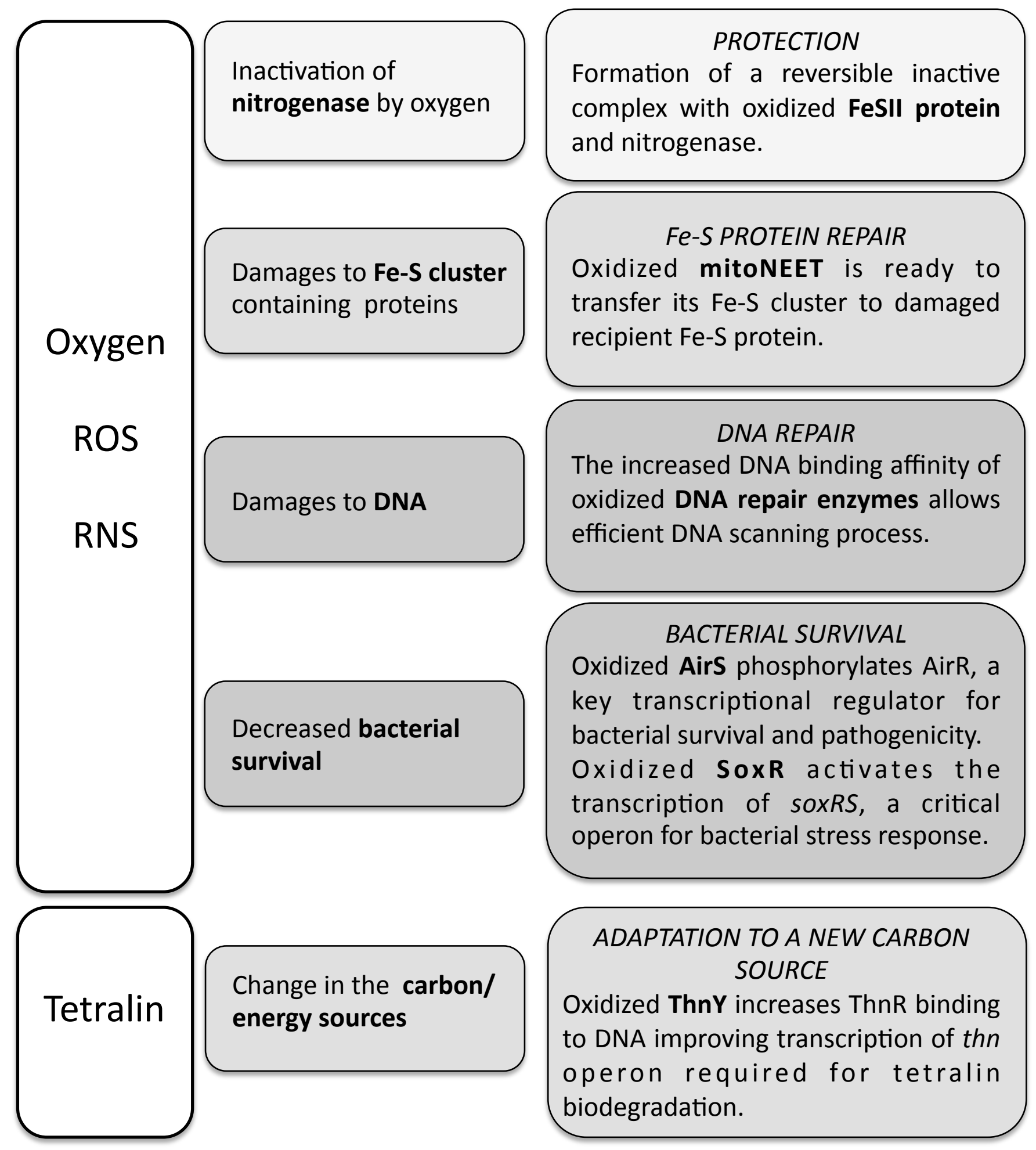

Figure 7 